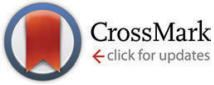

Cite this: Chem. Commun., 2017, 53,298

Received 9th September 2016, Accepted 27th October 2016

DOI: $10.1039 / c 6 c c 07377 h$

www.rsc.org/chemcomm

\section{Properties and emerging applications of mechanically interlocked ligands}

\author{
James E. M. Lewis, Marzia Galli and Stephen M. Goldup* \\ Mechanically interlocked molecules have a long and rich history as ligands thanks to the key role \\ coordination chemistry has played in the development of high yielding passive template syntheses \\ of rotaxanes and catenanes. In this Feature Article, we highlight the effect of the mechanical bond \\ on the properties of metal ions bound within the sterically hindered environment of the macrocycle \\ cavity, and discuss the emerging applications of interlocked ligands in catalysis, sensing and supra- \\ molecular materials.
}

\section{Introduction}

Species in which two or more covalent sub-components are entangled and held together not through direct covalent interactions but through the inability of bonds and atoms to pass through one another are referred to as mechanically interlocked molecules (MIMs). ${ }^{1}$ The archetypal examples of MIMs are catenanes, consisting of two or more mechanically interlocked macrocycles, and rotaxanes which, in their simplest form, consist of a macrocyclic component wrapped around a linear axle, with dissociation of the subcomponents prevented by bulky stopper units at the axle termini.

Initially an esoteric curiosity, the exploration of MIMs for a variety of applications has increased dramatically over the last three decades, a trend inextricably associated with the development of template-directed methods for their synthesis. ${ }^{1}$ The first such high yielding method was reported by Sauvage and co-workers in 1983 and relied on the predictable tetrahedral coordination geometry of a $\mathrm{Cu}^{\mathrm{I}}$ ion with phenanthroline ligands to arrange macrocycle $\mathbf{1}$ and macrocycle precursor $\mathbf{2}$ perpendicular to one another in such an orientation that cyclisation of $\mathbf{2}$ gave relatively facile and high yielding access to [2]catenane 3 (Fig. 1). ${ }^{2}$ Soon after, Gibson and co-workers demonstrated that the introduction of bulky stoppering units to 2 rather than cyclisation, using the same $\mathrm{Cu}^{\mathrm{I}}$-phenanthroline passive template, ${ }^{3}$ gave the corresponding [2] rotaxane species. ${ }^{4}$

Sauvage's seminal work on the $\mathrm{Cu}^{\mathrm{I}}$-phenanthroline template inspired the development of many other template-directed methods, including a great many examples based on metal ions. MIMs prepared by these methods inherently possess the ability to bind metal ions between the two components in a mechanically

Chemistry, University of Southampton, University Road, Southampton, SO17 1BJ, UK. E-mail: s.goldup@soton.ac.uk

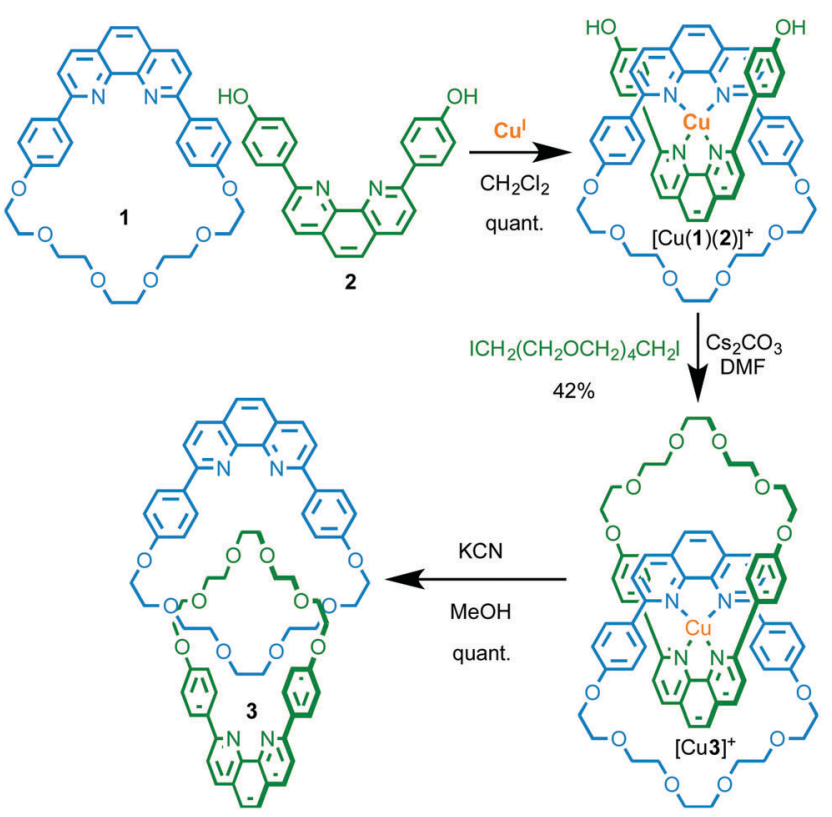

Fig. 1 Sauvage's seminal passive $\mathrm{Cu}^{\prime}$-template directed synthesis of [2]catenane $\mathbf{3}^{2}$

chelating manner where the donor atoms are linked via the mechanical bond. Perhaps most famously, this has been further capitalised on in the development of molecular switches where the relative position of the covalent sub-components (their co-conformation) is controlled by metal-ligand interactions. ${ }^{1}$

The synthesis and operation of interlocked molecular machines using such passive metal templates has been comprehensively reviewed elsewhere and will not be covered here. ${ }^{1}$ Instead, in this Feature Article, we shall discuss the effect of the mechanical bond on the chemistry of coordinated metal ions and emerging applications of mechanically interlocked ligand (MIL) scaffolds, 
focussing on MIMs as ligands for catalysis, MILs as sensors, and finally MIMs as structural components within metallosupramolecular architectures.

\section{The effect of the mechanical bond on the chemistry of coordinated metal ions}

Given the preponderance of metal ion templated syntheses of MIMs and the inherent ability of the products to bind metal ions strongly in an endohedral manner between the two covalent components, this is unsurprisingly the most prominent mode of coordination by MIM-based ligands. Furthermore, these "mechanically chelating" ligands inherently place metal ions in an unusual sterically shielded and conformationally restricted environment, and this can have significant consequences for their properties.

Firstly, the interlocked product of a passive metal template synthesis typically forms more kinetically stable complexes with the metal ion template than the precursor ligands. Sauvage observed this phenomenon early in the development of his $\mathrm{Cu}^{\mathrm{I}}$-phenanthroline template; the templating $\mathrm{Cu}^{\mathrm{I}}$ ion remained bound to catenane 3 following column chromatography, requiring the use of ${ }^{-} \mathrm{CN}$ to achieve demetallation. ${ }^{2}$ Subsequent studies demonstrated that the rate of $\mathrm{Cu}^{\mathrm{I}}$ removal by $\mathrm{KCN}$ was lower in the case of catenane 3 than analogous non-interlocked phenanthroline complexes (Fig. 2). ${ }^{5}$ Sauvage termed this increased kinetic stability the "catenand" effect by analogy with the cryptate effect, $^{7}$ and attributed the observed stabilisation to the pre-organisation of the ligand donor atoms in the catenane architecture, combined with steric protection of the metal centre, afforded by the organic foliage of the MIM itself.

Secondly, endotopic coordination within the binding pocket of catenane $\mathbf{3}$ was shown to alter the redox chemistry of the bound metal ion. Sauvage and co-workers found that catenane 3 is capable of binding a range of metal cations $\left(\mathrm{Li}^{\mathrm{I}}, \mathrm{Ag}^{\mathrm{I}}, \mathrm{Zn}^{\mathrm{II}}, \mathrm{Cd}^{\mathrm{II}}\right.$, $\mathrm{Co}^{\mathrm{II}}, \mathrm{Ni}^{\mathrm{II}}, \mathrm{Fe}^{\mathrm{II}}, \mathrm{Pd}^{\mathrm{II}}$ ) other than $\mathrm{Cu}^{\mathrm{I}}$, demonstrating that, although

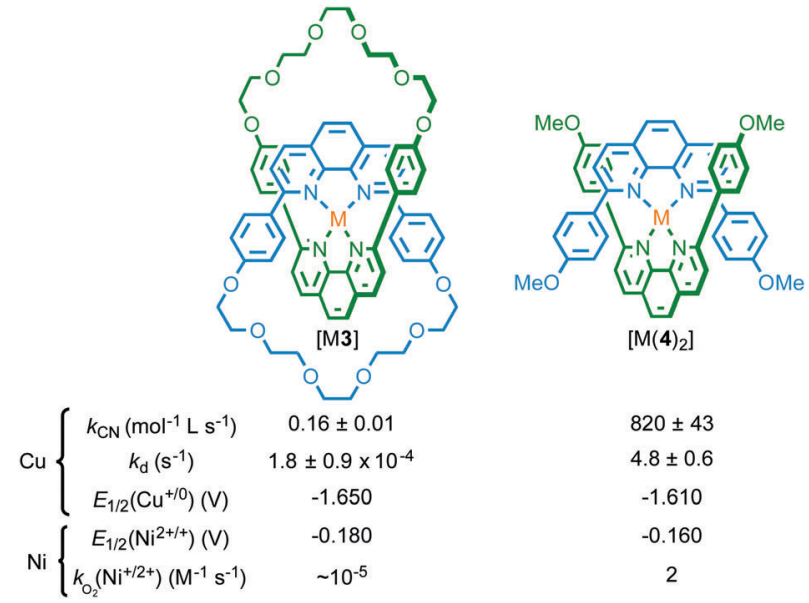

Fig. 2 Effect of the mechanical bond on the stability and electrochemistry of metal complexes of catenane $[M(3)]$ compared with non-interlocked analogue $\left.\left[\mathrm{M}(\mathbf{4})_{2}\right]\right]^{5,8}$ the ligand pocket is restricted, it is flexible enough to accommodate ions of different radii; indeed, the enforced association of the phenanthroline ligands in catenane 3 allowed tetracoordinate complexes of $\mathrm{Li}^{\mathrm{I}}$ and $\mathrm{Fe}^{\mathrm{II}}$ to be isolated, whereas complex formation was not observed with non-interlocked ligand $4 .{ }^{8,9}$ However, the mechanical bond of catenane 3 significantly altered the accessible oxidation states of the bound metal ions by disfavouring higher oxidation states; $\mathrm{Fe}^{\mathrm{III}}$ and $\mathrm{Co}^{\mathrm{III}}$ proved inaccessible under the experimental conditions used. ${ }^{8}$ The inability to access higher oxidation states was attributed to the catenane structure preventing coordination of additional ligands to provide the higher coordination numbers required to stabilise the high charge density of the trivalent cations. Conversely, reduction potentials to access lower oxidation states $\left(\mathrm{Cu}^{\mathrm{I} / 0}\right.$ and $\left.\mathrm{Ni}^{\mathrm{II} / \mathrm{I}}\right)$ were not significantly altered in the interlocked structure.

Finally, the mechanical bond also modifies the kinetics of chemical oxidation. Thus, although $\left[\mathrm{Ni}^{\mathrm{II}}(3)\right]$ and non-interlocked analogue $\left[\mathrm{Ni}^{\mathrm{II}}(4)_{2}\right]$ were reduced at comparable potentials to give spectroscopically similar $\mathrm{Ni}^{\mathrm{I}}$ species, with EPR studies confirming the formally $d^{9}$ electronic state of the $\mathrm{Ni}^{\mathrm{I}}$ ion in both cases, the rate constant for oxidation of catenane complex [ $\left.\mathrm{Ni}^{\mathrm{I}}(3)\right]$ by dissolved $\mathrm{O}_{2}$ in $\mathrm{CH}_{2} \mathrm{Cl}_{2}$ solution was found to be $10^{5}$ times smaller than the non-interlocked analogue. ${ }^{10}$

Thus the mechanical bond in catenanes has been shown to significantly alter the coordination chemistry, stability and redox properties of the interlocked metal complex. The observation of similar effects in the case of rotaxanes is much less common, at least in part because the environment of the mechanical bond is typically less constrained than in catenanes. However, similarly to Sauvage's report in the case of catenane 3, Leigh and co-workers have demonstrated that the enforced association of convergent binding sites within a rotaxane can give rise to complexes that are not accessible in the case of the corresponding non-interlocked ligands. ${ }^{11}$ More recently, we have demonstrated that the active template Cu-mediated alkyne-azide cycloaddition (AT-CuAAC) ${ }^{12}$ approach to rotaxanes can be used to generate very hindered interlocked molecules ${ }^{13}$ to the point where this unusual environment can stabilise a reactive $\mathrm{Cu}^{\mathrm{I}}$-organometallic species; when $\mathrm{N}^{\mathrm{i}} \mathrm{Pr}_{2} \mathrm{Et}$ is employed to accelerate the AT-CuAAC reaction, the isolated product is not the expected rotaxane, but interlocked $\mathrm{Cu}^{\mathrm{I}}$-triazolide $[\mathrm{Cu}(8)]$ intermediate of the CuAAC reaction (Fig. 3). ${ }^{14}$ Given the well-established protolytic instability of $\mathrm{Cu}^{\mathrm{I}}$ organometallic species, the stability of $[\mathrm{Cu}(8)]$ is remarkable; not only does it survive aqueous work up with $\mathrm{NH}_{3}$-EDTA, it even displays an appreciable stability in the presence of a variety of carboxylic acids. Tellingly, the time taken for protonation of the $\mathrm{Cu}-\mathrm{C}$ bond is strongly correlated with the steric bulk of the acid.

It is perhaps surprising that, although the catenand effect and the modification of redox behaviour of metal ions were two of the first concrete examples of the effect of mechanical bonding on the chemistry of metal complexes, both remain largely unused as a method for generating metal complexes with tailored properties. Indeed, although a great many interlocked ligands with endohedrally bound metals have been reported, in many cases 


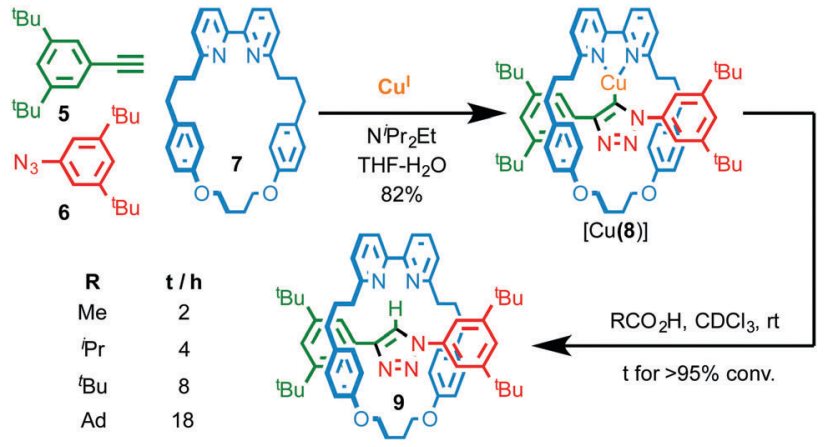

Fig. 3 Synthesis of $\mathrm{Cu}^{\prime}$ triazolide $[\mathrm{Cu}(\mathbf{8})]$ under aqueous conditions and the effect of carboxylic acid size on the rate of protodemetallation. ${ }^{14}$ $\mathrm{Ad}=1$-adamantyl.

detailed comparisons with the corresponding non-interlocked metal complex are not discussed. Given the many potential applications of metal ions, for instance in bioimaging through radiochemical, optical and magnetic modes, the key role complex stability plays in their biocompatibility, and the flexibility provided by mechanically chelating ligands,${ }^{15}$ this is clearly an area that warrants further investigation.

\section{Mechanically interlocked ligands for catalysis}

Despite the large number of interlocked metal complexes reported to date, the majority of these are poorly suited to catalytic applications; mechanically chelating ligands produced through metalbased passive template methods are typically coordinatively saturated and sterically hindered, limiting their catalytic potential. For this reason, relatively few metal complexes of mechanically interlocked ligands have been reported as catalysts. However, the unusual properties of the mechanical bond, principally the restricted relative motion of the covalent sub-components and the ability to generate a crowded but flexible reaction environment, have been shown to impart unusual properties on catalysts based on interlocked molecules.

\section{Intramolecular transformations of metal-ion containing MIMs}

Architectures in which a catalytically active metal ion is bound to the ring component of a rotaxane bear comparison with information processing enzymes such as DNA polymerase III that operate by threading their polymeric template through a toroidal clamp bearing the catalytic subunit. ${ }^{16}$ This arrangement of catalyst and substrate results in high processivity - the number of catalytic cycles before the catalyst and substrate separate. Inspired by these natural systems, in 2003 Rowan and Nolte reported a rotaxane in which an endotopic $\mathrm{Mn}^{\mathrm{III}}$ centre in the macrocycle was demonstrated to epoxidise a threaded polybutadiene substrate in a highly processive manner (Fig. 4a). ${ }^{17}$ The interlocked catalyst-substrate architecture is assembled through $\pi-\pi$ stacking interactions between a viologen unit in the axle and the electron rich aromatic units of a glycoluril-clip macrocycle. Subsequent addition of a bulky pyridine ligand

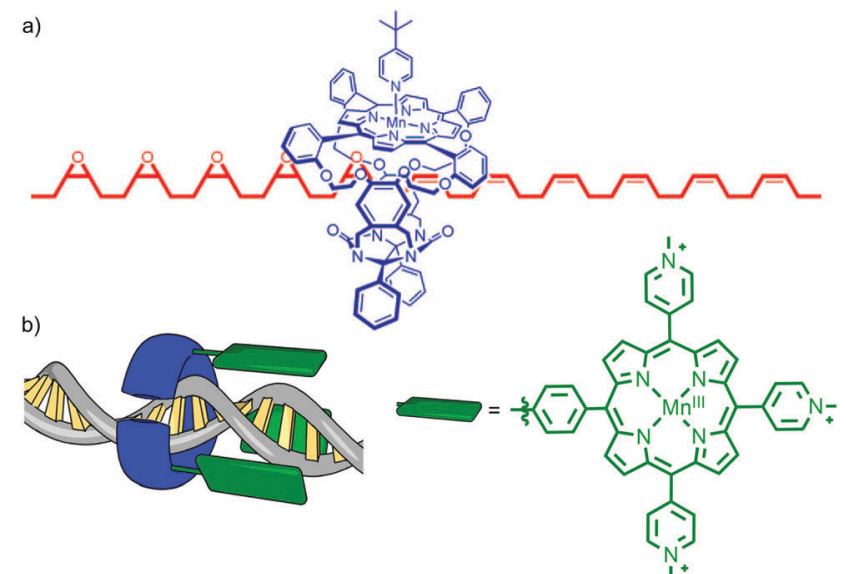

Fig. 4 (a) Partial structure of Rowan and Nolte's DNA polymerase mimic showing the macrocycle containing the $\mathrm{Mn}$ porphyrin catalyst and the partially oxidised polybutadiene axle. ${ }^{17}$ Adapted from ref. $17 c$. Copyright 2007 National Academy of Sciences. (b) a cartoon of the recently reported biohybrid mechanically interlocked catalyst. ${ }^{18}$ Adapted by permission from ref. 18. Copyright 2013 Nature Publishing Group.

that binds to the $\mathrm{Mn}^{\mathrm{III}}$ centre blocks the outer face of the Mn-porphyrin catalytic unit, ensuring that catalysis can only take place in the macrocycle cavity. Addition of an oxidant (PhIO) results in the rapid epoxidation of the threaded substrate with catalysis taking place inside the cavity of the macrocycle. In addition to ensuring extremely high processivity, this unusual catalyst-substrate arrangement leads to high selectivity for the trans epoxide product $(80: 20$ trans-cis $)$ whereas the corresponding intermolecular reaction produces the cis epoxide $(20: 80)$. Subsequent studies of the threading and sliding process indicate that the enzyme mimic operates by randomly sliding along its macromolecular substrate rather than transforming each individual alkene in the order they are encountered. More recently, the same authors reported the extension of this approach to the site selective oxidation of DNA by tethering a similar $\mathrm{Mn}^{\text {III }}$ porphyrin to the toroidal sliding clamp protein of bacteriophage $\mathrm{T} 4$, to produce a biohybrid mechanically interlocked catalyst (Fig. 4 b). ${ }^{18}$

In Rowan and Nolte's systems, the catalytic unit of the macrocycle component was not employed directly in the synthesis of the interlocked structure. More recently, Takata and co-workers reported examples of rotaxanes assembled using a $\mathrm{Pd}^{\mathrm{II}}$ passive template in which the metal ion can then be used to catalyse the conversion of allylic carbamate units in the axle to produce oxazolidinone rings (Fig. 5). ${ }^{19}$ Coordination of pyridine $\mathbf{1 1}$ to $\mathrm{Pd}$ complex $[\mathrm{Pd}(\mathbf{1 0})(\mathrm{MeCN})]$ produced threaded complex $[\operatorname{Pd}(\mathbf{1 0})(\mathbf{1 1})]$ which was subsequently trapped by reaction with an isocyanate to give rotaxane $\mathrm{Pd}$ complex $[\operatorname{Pd}(\mathbf{1 2})]$. Heating $[\operatorname{Pd}(\mathbf{1 2})]$ in the presence of $\mathrm{Mg}(\mathrm{OH})_{2}$ resulted in the cyclisation of the urethane units to produce $[\operatorname{Pd}(\mathbf{1 3})]$. Test reactions demonstrated that both the $\mathrm{Pd}^{\mathrm{II}}$ complex and the base were required for the reaction to take place efficiently. Furthermore, the reaction of the non-interlocked axle with the same macrocyclic $\mathrm{Pd}^{\mathrm{II}}$ complex led to no conversion demonstrating that the reaction takes place within the cavity of the rotaxane. ${ }^{20}$ 

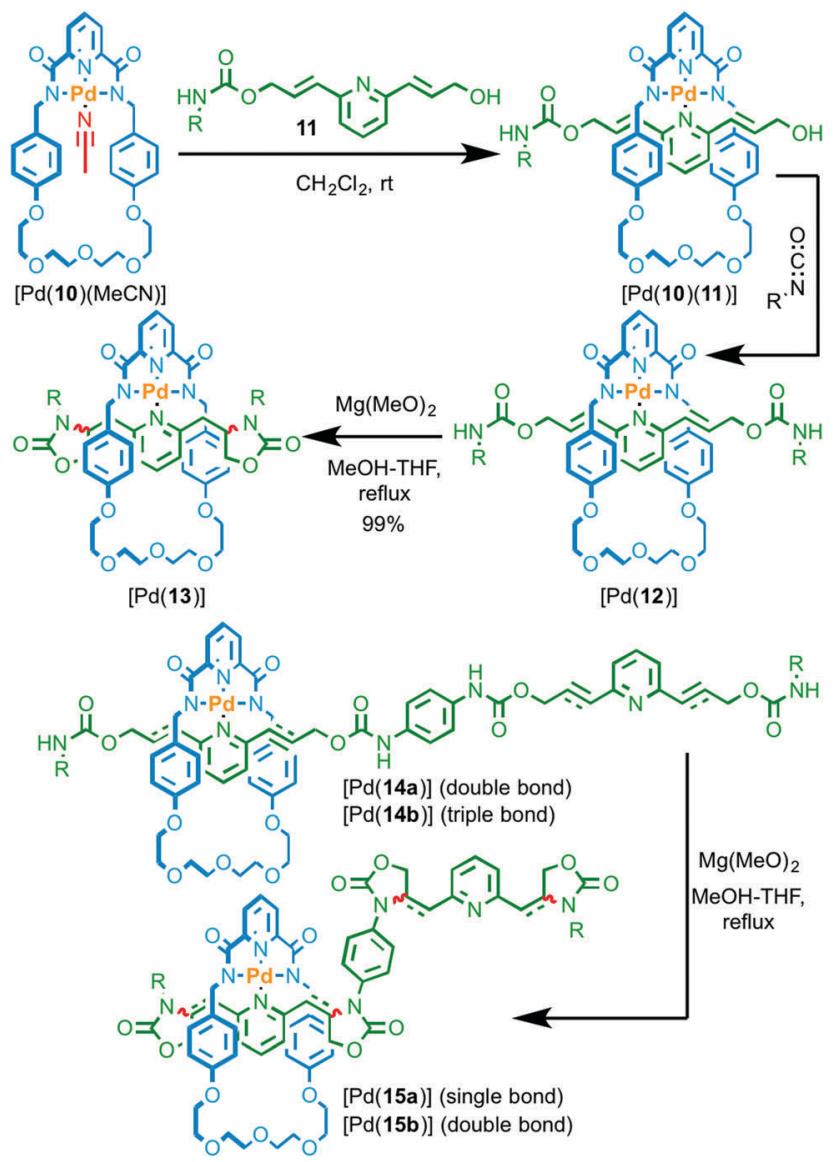

Fig. 5 Intramolecular cyclisation of allylic and propargylic carbamate groups by a threaded macrocyclic Pd catalyst. $\mathrm{R}=4-\mathrm{C}_{6} \mathrm{H}_{4}\left(\mathrm{C}\left(4-{ }^{t} \mathrm{BuC}_{6} \mathrm{H}_{4}\right)_{3}\right){ }^{19}$

The reaction could be extended to rotaxane $[\mathrm{Pd}(\mathbf{1 4 a})]$ containing four allyl groups and an excellent yield of tetra-cyclised product $[\operatorname{Pd}(\mathbf{1 5 a})]$ was maintained $(99 \%)$. However, when propargylic rotaxane $[\operatorname{Pd}(\mathbf{1 4 b})]$ was reacted under the same conditions, a much lower yield of the corresponding tetra-oxazolone product $[\operatorname{Pd}(\mathbf{1 5 b})]$ was obtained $(16 \%)$. Although the oxazolone unit of $[\operatorname{Pd}(\mathbf{1 5 b})]$ is unstable under the reaction conditions, inherently reducing the yield of this reaction, the difference in yield between $[\operatorname{Pd}(\mathbf{1 5 a})]$ and $[\operatorname{Pd}(\mathbf{1 5 b})]$ was, in part, attributed to the inability of the macrocycle to move freely along the axle in intermediates leading to $[\operatorname{Pd}(\mathbf{1 5 b})]$. Conversely, the macrocycle can move freely in the case of more flexible $[\operatorname{Pd}(\mathbf{1 5 a})]$. This suggests that the modification of the axle is once again not sequence-processive, with the cyclisation reaction taking place by a random walk pathway.

Recently, Saito and co-workers reported the transformation of rotaxane 16, whose axle contains a diyne unit, into pyrrolecontaining rotaxane $\mathbf{1 7}$ by addition of aniline to the diyne unit mediated by a $\mathrm{Cu}^{\mathrm{I}}$ ion coordinated in the macrocyclic cavity (Fig. 6) ${ }^{21}$ The rate of the double hydroamination reaction was found to be significantly higher in the case of the interlocked structure than the non-interlocked axle with a range of $\mathrm{Cu}^{\mathrm{I}}$ sources, confirming that the reaction is significantly accelerated by the endotopically bound $\mathrm{Cu}^{\mathrm{I}}$ ion in rotaxane 16. By varying the size of

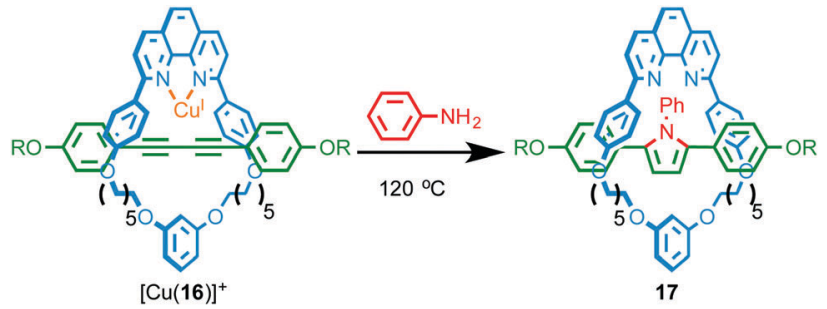

Fig. 6 Double hydroamination of rotaxane 16 mediated by an endotopically coordinationed $\mathrm{Cu}^{\prime}$ ion. ${ }^{21}$

the aniline nucleophile employed the authors were able to control the rate of macrocycle shuttling in the product.

These examples demonstrate that metal ions bound within the macrocyclic cavity of rotaxanes can enable reactions of the axle that are hard to perform otherwise and, in some cases, lead to high processivity when transforming multiple functional groups, suggesting potential applications in the post-synthetic modification of polymers. However, unlike the enzymes they set out to mimic, in the systems disclosed to date the macrocyclic catalyst explores the axle and randomly transforms the functional groups. If these systems are to deliver sequence controlled postsynthetic polymer modification, methods are needed to match the rate of macrocycle motion to the rate of the catalytic process, or the development of other strategies to control the relative position of the macrocycle and axle, as has been demonstrated in related systems relying on organocatalysis. ${ }^{22}$

\section{MIM complex-based catalysts with exogenous substrates}

The sterically crowded nature of the mechanical bond can profoundly affect the reactivity of functional groups on the interlocked components ${ }^{23}$ including bound metal ions ( $c f$. the catenand effect). Logically, this effect should extend to metal ions capable of catalysing reactions between exogenous substrates and thus interlocked ligands present an interesting opportunity for the development of new catalysts with unusual properties. However, only limited examples of ligands that take advantage of this effect have been reported to date.

In 2008 Hagiwara and co-workers described catenane 18, which is functionalised by two phosphine moieties, and synthesised using a hydrogen bonding passive template (Fig. 7). ${ }^{24}$ This ligand has the potential to act as an unusual bidentate phosphine in which the bite angle is determined by the mechanical bond. Catenane 18 was investigated in the Pd-catalysed SuzukiMiyaura cross-coupling reaction between bromobenzene and phenylboronic acid. Although the reaction was successful, producing biphenyl in $66 \%$ yield, no comparison was made

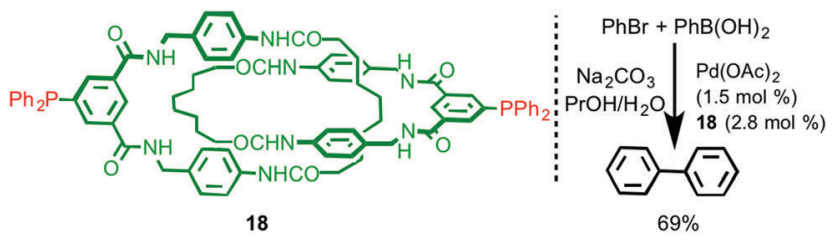

Fig. 7 Suzuki-Miyaura coupling reaction with catenane 18 as a ligand. ${ }^{24}$ 
with the non-interlocked ligand making it hard to assess the effect of the mechanical bond on the reaction. Furthermore, the ratio between the metal ion (1.5 mol\%) and the potentially bidentate ligand $18(2.8 \mathrm{~mol} \%)$ suggests that only one of the two phosphine moieties is involved in coordination to Pd.

As in the case of Rowan and Nolte, and Takata's catalysts above, one of the advantages of interlocked molecules is the ability of the covalent components to move relative to one another. Osakada and co-workers investigated the potential advantages of this effect for transformation of exogenous substrates by synthesising [3] rotaxane $\left[\mathrm{Pd}_{2}(\mathbf{1 9})(\mathrm{Cl})_{4}\right]$ in which both macrocycles contain an exotopically ligated $\mathrm{Pd}^{\mathrm{II}}$ ion (Fig. 8). ${ }^{25}$ They then investigated this binuclear $\mathrm{Pd}^{\mathrm{II}}$ complex as a catalyst for the Heck cyclisation of bis-alkene 20 and bis-iodobenzene 21. The reaction was successful, producing target macrocycle 22 in higher yield and with greater selectivity than the same reaction mediated by $\operatorname{Pd}(\mathrm{OAc})_{2}$ in the presence of four equivalents of $\mathrm{PPh}_{3}$. The authors proposed that this might be due to the rotaxane architecture allowing both metal centres to react with the substrates simultaneously to promote macrocyclisation due to the ability of the two macrocycles to move relative to one another. This is, to date, the only example of using the mechanical bond to provide a flexible environment for bimetallic catalysis, an exciting potential application of MIMbased catalysts. ${ }^{26}$

Leigh and co-workers reported a chiral [2] rotaxane ligand for a Nickel-catalysed enantioselective Michael addition (Fig. 9). ${ }^{27}$ Rotaxane $\mathbf{2 3}$, which is synthesised using an active template methodology, is unusual in that it can form coordinatively unsaturated endotopically bound complexes. The $\mathrm{NiBr}_{2}$ complex of rotaxane 23 mediates the Michael addition between diethyl malonate and trans- $\beta$-nitrostyrene to give the product in $86 \%$ ee. Rotaxane 23 delivers the product in higher ee than corresponding acyclic amine ligand 24 (86\% and $36 \%$ ee respectively), although the rotaxane-mediated reaction is an

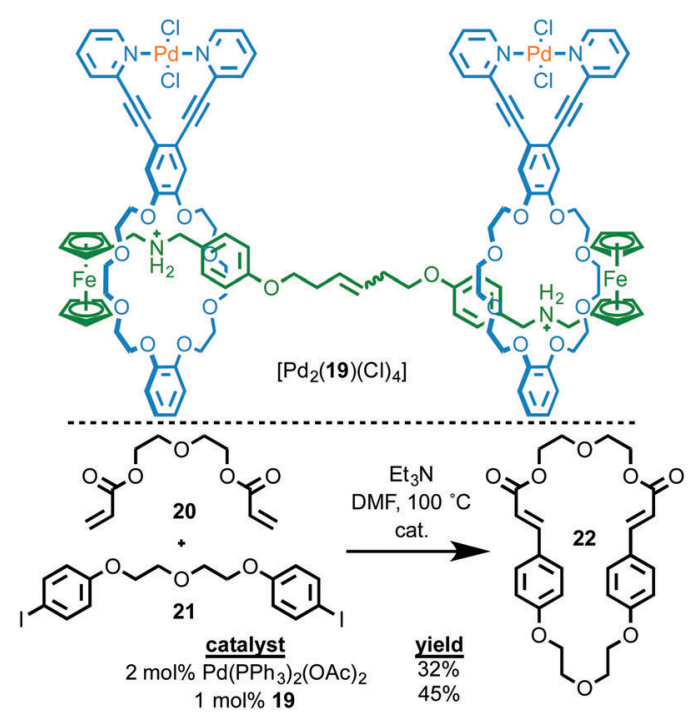

Fig. 8 Ring-closing Mizoroki-Heck reaction by [3]rotaxane Pd complex $\left[\mathrm{Pd}_{2}(\mathbf{1 9})(\mathrm{Cl})_{4}\right]{ }^{25}$

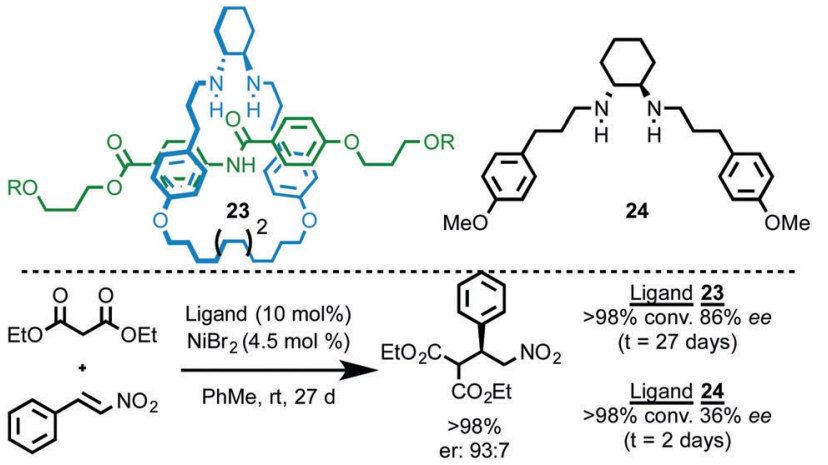

Fig. 9 An enantioselective Michael-addition reaction mediated by a rotaxane ligand. ${ }^{27}$

order of magnitude slower ( 27 days $v s .48 \mathrm{~h}$ ), presumably due to the hindered nature of the metal centre.

Recently we reported an interlocked gold catalyst with a number of unusual properties. ${ }^{28}$ Rotaxane $\mathrm{Au}^{\mathrm{I}}$-phosphine complex $[\mathrm{Au}(25)(\mathrm{Cl})]$ was synthesised using an AT-CuAAC approach and its performance in the cyclopropanation reaction between styrene and propargyl ester 26 was compared with the corresponding non-interlocked catalyst. Surprisingly, although the non-interlocked catalyst mediates the cyclopropanation of styrene in moderate diastereoselectivity, rotaxane catalyst $[\mathrm{Au}(\mathbf{2 5})(\mathrm{Cl})]$ fails to mediate the reaction at all (Fig. 10).

Ultimately, ${ }^{1} \mathrm{H}$ NMR analysis suggested that binding of the bipyridine donors to the $\mathrm{Au}^{\mathrm{I}}$ centre inhibited the interlocked catalyst. Accordingly, addition of a catalytically innocent guest $\left(\mathrm{Cu}^{\mathrm{I}}, \mathrm{Zn}^{\mathrm{II}}\right)$, that binds inside the macrocycle cavity, reverses the inhibition and switches the catalyst on, leading to higher yields and diastereoselectivity compared with the non-interlocked axle. The enhanced diastereoselectivity of $[\mathrm{Au}(\mathbf{2 5})(\mathrm{Cl})]$ was rationalised by considering the buried volume (\%Vbur - a measure of the space occupied by ligands in the coordination sphere of metal ions $)^{29}$ values of the rotaxane and non-interlocked $\mathrm{Au}$ complexes, which demonstrated the enhanced steric hindrance provided by the mechanical bond. ${ }^{30}$ Intriguingly, not only does the identity

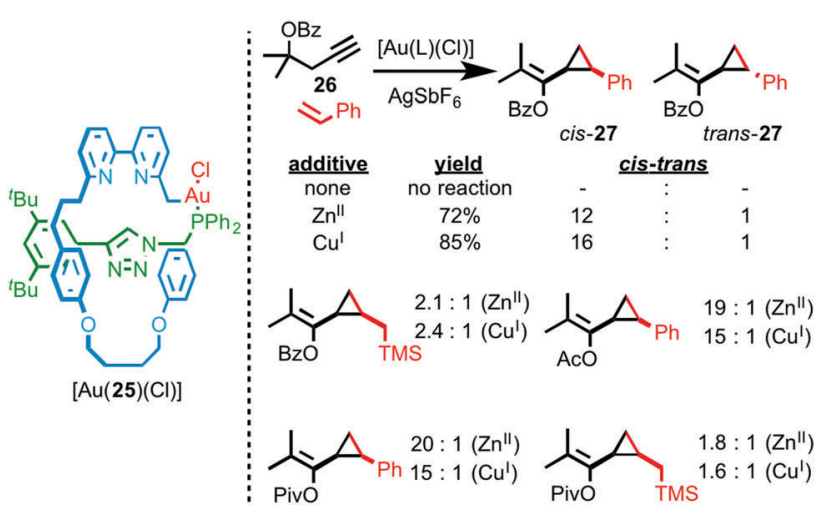

Fig. 10 Sterically hindered, stimuli responsive rotaxane catalyst $[\mathrm{Au}(\mathbf{2 5})(\mathrm{Cl})]$ was studied in the Au-mediated cyclopropanation reaction shown and the effect of catalytically innocent cofactors on the diastereoselectivity of the reaction demonstrated. ${ }^{28}$ 
of the additive influence the yield and diastereoselectivity of the reaction catalysed by $[\mathrm{Au}(\mathbf{2 5})(\mathrm{Cl})]$, the "best" additive varies depending on the substrate, with aryl esters favouring $\mathrm{Cu}^{\mathrm{I}}$ as the co-factor and alkyl esters giving the highest selectivity in the presence of $\mathrm{Zn}^{\mathrm{II}}$. This variation in $\mathrm{dr}$ with additive was rationalised by the effect of additive binding on the shape of the catalyst and thus the steric hindrance around the reaction site.

The development of rotaxanes as catalysts is still in its early stages. In order to demonstrate the key advantages of the mechanical bond in catalysis, in particular the effect of the crowded, flexible environment of the mechanical bond, it is important that proper controls are provided for comparison and this is not always trivial. For instance, the behaviour of [3] rotaxane $\left[\mathrm{Pd}_{2}(19)(\mathrm{Cl})_{4}\right]$ and rotaxane ligand 23 , in both of which the catalytic metal ion is bound by the macrocyclic component, were compared with acyclic non-interlocked catalysts which makes it hard to tease apart the potential influences of ligand topology ${ }^{31}$ and the mechanical bond. This point notwithstanding, it is clear that interlocked ligands for catalysis bear further investigation as the studies above suggest the potential for the mechanical bond to influence the activity, chemo- and stereoselectivity of catalysed reactions.

\section{Mechanically interlocked ligands as sensors}

Rotaxanes and catenanes have the proven potential to act as hosts for ions and small molecules by binding the guest in the crowded environment created by the mechanical bond. ${ }^{32}$ The extension of this property to sensors requires the development of systems that display a "readable" signal (typically optical or electrochemical) that selectively distinguish between different potential guests.

\section{MILs that report the binding of metal ions}

A simple way to design a metal responsive MIM is by employing the mechanically chelating ligand produced in a metal ion mediated passive template synthesis to bind the analyte. Swager and co-workers demonstrated this approach by employing Sauvage's phenanthroline- $\mathrm{Cu}^{\mathrm{I}}$ template to produce rotaxane 28 that displays exciplex emission in the metal-free state (Fig. 11). ${ }^{33 a}$ Addition of $\mathrm{Zn}^{\mathrm{II}}$ to a solution of 28 leads to quenching of the longer wavelength emission as the energy levels of the coordinated phenanthroline moiety and relative orientation of the chromophores in metal complex $[\mathrm{Zn}(28)]^{2+}$ disfavour exciplex formation..$^{34}$ Other metal ions also quenched the exciplex emission. The authors later extended this system to the solid state by electropolymerisation of an interlocked precursor and demonstrated that $\mathrm{Zn}^{\mathrm{II}}$ or $\mathrm{Cu}^{\mathrm{I}}$ binding alters the electrical conductivity and optical properties of the conjugated polymer. ${ }^{33 b, c}$

Rotaxane 28 relies on metal binding in the mechanically chelating ligand produced in the passive template synthesis to induce electronic and conformational changes that result in optical and electrochemical read out. It is also possible to use metal binding in systems where the metal binding unit is not residual

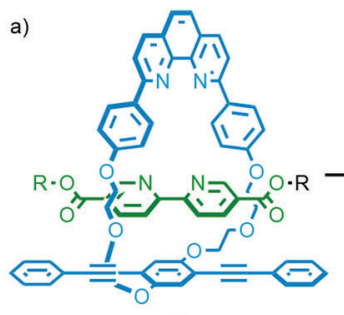

28

b)

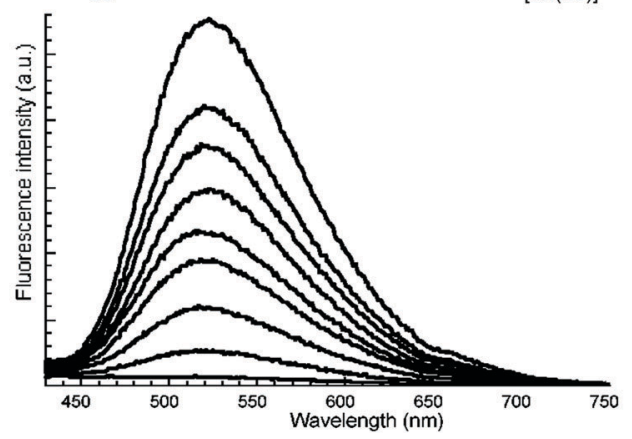

Fig. 11 (a) Emissive rotaxane 28; (b) the response of $\mathbf{2 8}$ to $\mathrm{Zn}$ ". 33a Adapted with permission from ref. 33a. Copyright 2001 American Chemical Society.

from the method of synthesis. Catenane 29, which is synthesised through a hydrogen bond directed strategy, exhibits a switch on fluorescent response in the presence of $\mathrm{Zn}^{\text {II }}$ (Fig. 12). ${ }^{35}$ The origin of this effect is not entirely clear but it appears that the binding of $\mathrm{Zn}^{\mathrm{II}}$ interrupts the salt bridge between the amidine and carboxylate units, ${ }^{36}$ leading to enhanced relative motion of the two macrocycles, as shown by the loss of CD signal on complexation. Addition of a cryptand to sequester the $\mathrm{Zn}^{\mathrm{II}}$ ion regenerates the free ligand.

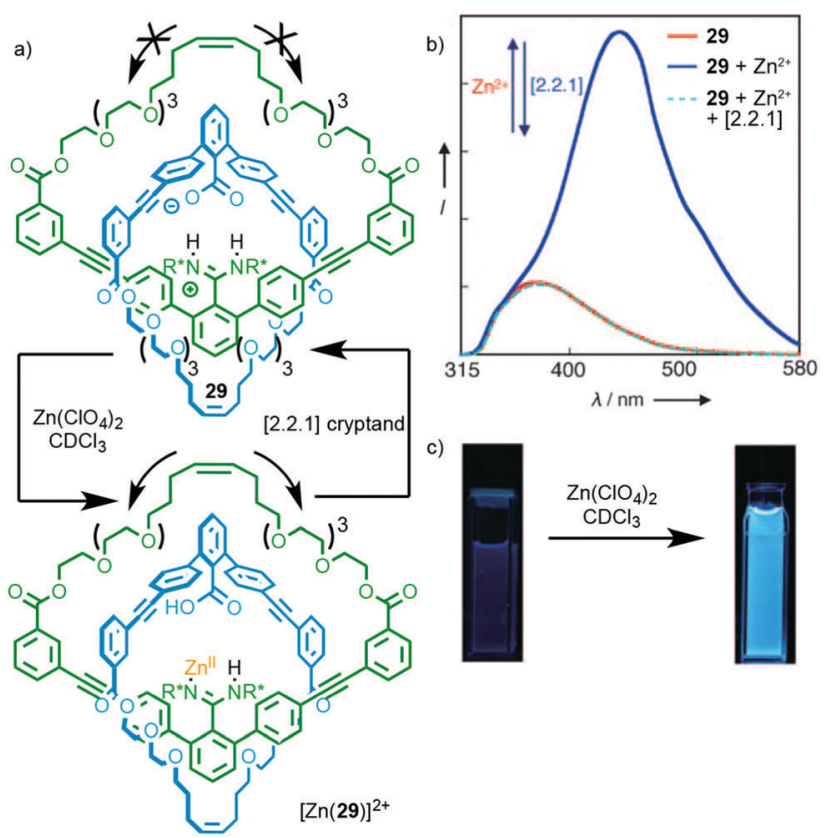

Fig. 12 (a) Catenane $\mathbf{2 9}$ synthesised using a salt-bridge template; (b) addition of $\mathrm{Zn}$ " interrupts the salt bridge leading to visibly enhanced fluorescence (c). ${ }^{35}$ Adapted with permission from ref. 35. Copyright (C) 2010 WILEY-VCH Verlag $\mathrm{GmbH} \&$ Co. KGaA, Weinheim. 


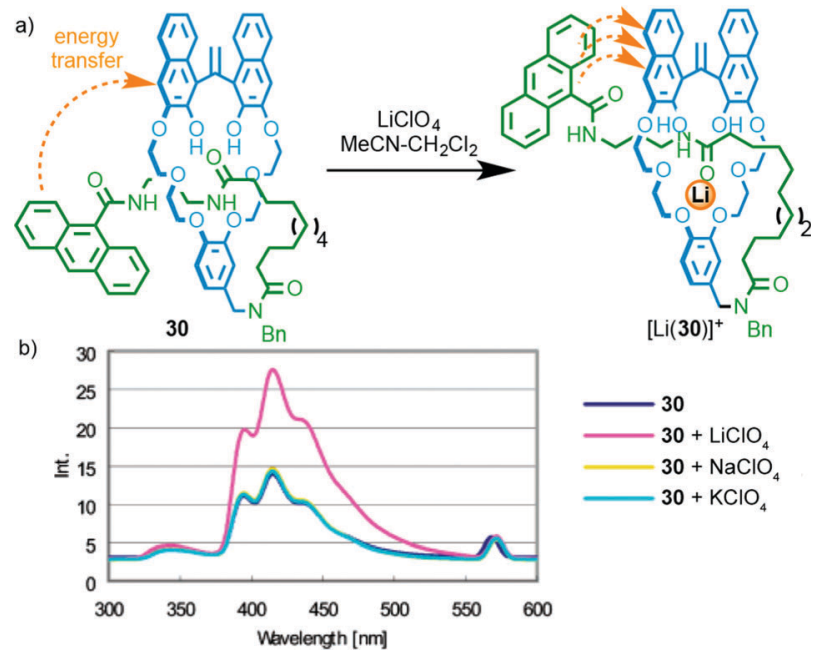

Fig. 13 (a) Li-selective rotaxane based host $\mathbf{3 0}$ and (b) its fluorescence response in the presence of group I metal ions. Adapted with permission from ref. 38. Copyright 2004 American Chemical Society.

In 2004 Hiratani and co-workers reported [1] rotaxane ${ }^{37}$ 30 that selectively binds $\mathrm{Li}^{\mathrm{I}}$ over other group I metal ions (Fig. 13); ${ }^{38}{ }^{1} \mathrm{H}$ NMR studies demonstrated that $\mathrm{Li}^{\mathrm{I}}$ was able to bind in the cavity formed between the crown ether macrocycle and the amide axle component, whereas $\mathrm{Na}^{\mathrm{I}}$ and $\mathrm{K}^{\mathrm{I}}$ did not bind. ${ }^{39}$ Furthermore, binding of $\mathrm{Li}^{\mathrm{I}}$ was proposed to lead to a (co)conformational change that brings the macrocycle and anthracene moiety into closer proximity. This in turn enhanced energy transfer between the naphthol moiety of the macrocycle and the anthracene moiety of the axle, resulting in an enhanced emission. The same authors later extended this approach to a [3]rotaxane that shows different coordination behaviour with $\mathrm{Li}^{\mathrm{I}}$ and the larger $\mathrm{Cs}^{\mathrm{I}}$ ion; ${ }^{40}$ while $\mathrm{Li}^{\mathrm{I}}$ is coordinated within the macrocycle cavity and forms a $2: 1$ complex, the larger $\mathrm{Cs}^{\mathrm{I}}$ ion is coordinated between the macrocycles in a 1:1 complex. Coordination of $\mathrm{Cs}^{\mathrm{I}}$ is reported to result in an increase in fluorescence intensity. ${ }^{41}$

Perhaps the best-known role of metal ions in the development of stimuli responsive MIMs is as molecular shuttles where addition or removal of metal ions leads to changes in the relative position of the interlocked components. ${ }^{1}$ Most of these systems are studied either by NMR or cyclic voltammetry. However, a small number of examples have been reported in which metal driven changes in the co-conformation leads to an optical output.

In $2008 \mathrm{Li}$ and co-workers demonstrated metal-responsive shuttle 31 that displays changes in optical output depending on its coordination state (Fig. 14). ${ }^{42}$ In the neutral state, the macrocycle occupies the amide station and photo-induced electron transfer from the amine moieties of the axle and macrocycle quenches the anthracene emission. Addition of $\mathrm{Li}^{\mathrm{I}}$ leads to an increase in emission that the authors propose is due to a change in orientation of the macrocycle on the amide station reducing the efficiency of the quenching process. Addition of $\mathrm{Zn}^{\mathrm{II}}$ to rotaxane $\mathbf{3 1}$ led to shuttling of the macrocycle from the amide station to the amine to provide the $\mathrm{Zn}^{2+}$ ion with a tetra-aza binding pocket.

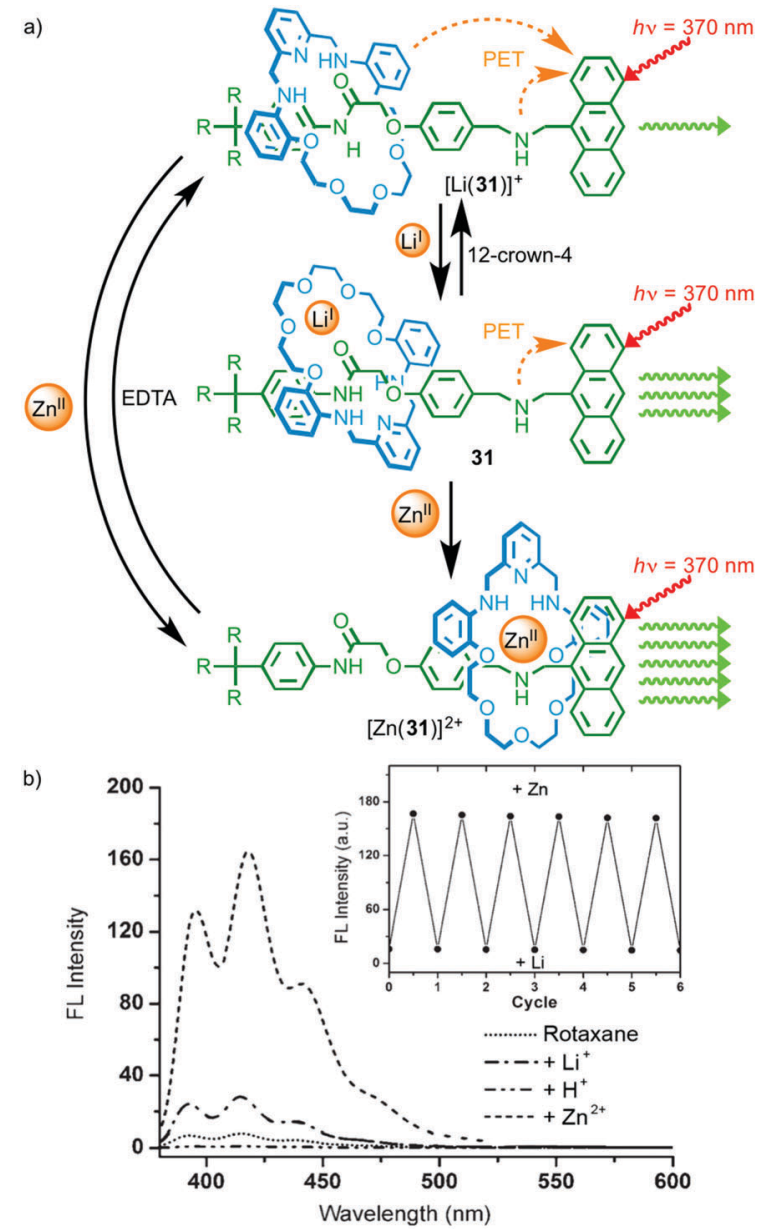

Fig. 14 (a) Metal responsive rotaxane $\mathbf{3 1}$ and (b) the observed changes in emission intensity depending on the coordination state. ${ }^{42}$ The exchange of $\mathrm{Zn}^{\prime \prime}$ for $\mathrm{Li}^{\prime}$ and vice versa was reversible over a number of cycles (inset). Adapted with permission from ref. 42. Copyright 2008 WILEY-VCH Verlag $\mathrm{GmbH} \& \mathrm{Co}$. KGaA, Weinheim.

This led to a much larger increase in the fluorescence output from the anthracene moiety as the amine in the axle and the macrocycle, now coordinated to $\mathrm{Zn}^{\mathrm{II}}$, are no longer able to quench the excited state by electron transfer.

Chiu and co-workers took a different approach in the development of rotaxane molecular shuttle 32, which also shows optical read out of metal ion binding (Fig. 15). ${ }^{43}$ In this case, the macrocycle occupies the bipyridinium station in the absence of metal ions. This exposes the squarine dye to the polar solvent $(\mathrm{MeCN})$ and results in quenching of the emission. Addition of $\mathrm{Na}^{\mathrm{I}}$ leads to shuttling of the macrocycle to the squarine station due to ion-dipole interactions between the crown ether windows of the macrocycle and the alkoxide moieties of the dye, shielding the dye from its environment and increasing the quantum yield of the squarine unit.

Relatively few examples of MIMs that display a "readable" signal on metal binding have been reported, despite the extremely large number of reported MIMs with metal binding units. Furthermore, although these examples produce a useful optical read-out, the majority do not report selectivity in the response; only in the 


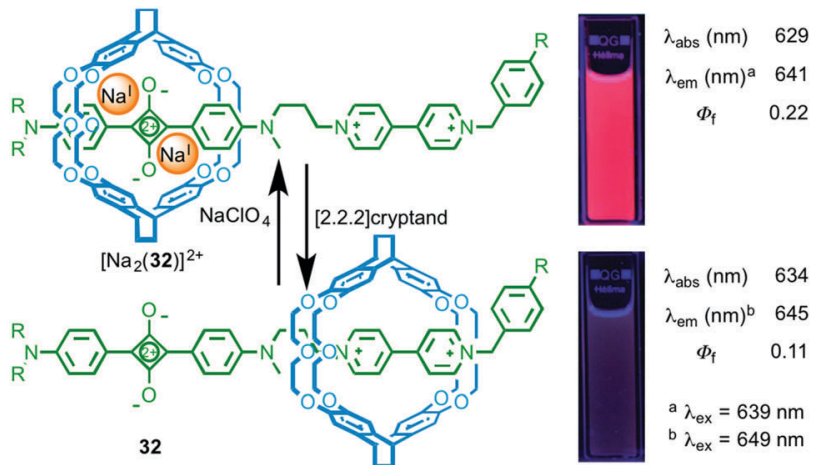

Fig. 15 Molecular shuttle 32 and its response to $\mathrm{Na}^{\prime}$ binding. ${ }^{43}$ Adapted with permission from ref. 43. Copyright 2008 WILEY-VCH Verlag GmbH \& Co. KGaA, Weinheim.

case of [1] rotaxane $\mathbf{3 0}$ and shuttle $\mathbf{3 1}$ are different responses reported for different metal ions. Thus, although all of the above examples demonstrate the potential of MIMs to bind metal ions and report that binding event, only Hiratani's system (Fig. 13) demonstrates the potential of this approach in the development of sensors by using the confined cavity of the rotaxane to develop a selective three dimensional binding site for a specific analyte. Given the proven potential of rotaxanes as sensors for small molecules and ions (see below), this seems to be an area with significant potential.

\section{Metal ions as reporter units in rotaxane-based sensors}

In contrast to the limited examples of selectivity in metal ion binding with MILs, interlocked hosts have been reported to bind to a range of anionic and small molecule analytes thanks to the restrictions imposed by the mechanical bond. ${ }^{32}$ Work from Beer and co-workers demonstrates both the potential of MIMs as selective hosts and an alternative application of metal-ligand interactions in sensor development; using the bound metal ion as a reporter unit.

As with metal ion templated MIMs, MIMs prepared via anion templation methods tend to have high affinities for anions. Importantly, the shape and size of the cavity generated between the MIM components often leads to high selectivity between anions, which in some cases contradicts those obtained with the non-interlocked components. For example, although the corresponding non-interlocked macrocycle alone binds most strongly to $\mathrm{Cl}^{\mathrm{I}}$, interlocked hydrogen bonding host 33, which contains a $\mathrm{Re}^{\mathrm{I}}$ centre bound to the exocyclic bipyridine unit, shows a greater than 10-fold higher binding constant for $\mathrm{HSO}_{4}{ }^{-}$(Fig. 16). The presence of the emissive $\mathrm{Re}(\mathrm{CO})_{3} \mathrm{Cl}$ complex allowed the binding of anions to be monitored by fluorescence spectroscopy (Fig. 16b). ${ }^{44,45}$ Recently Beer and co-workers have extended this approach to halogen bonding systems that display selectivity for iodide under aqueous conditions. ${ }^{46}$ The same approach has been extended to other emissive metal ion reporters including MILs for $\mathrm{Eu}^{\mathrm{III}},{ }^{47}$ and $\mathrm{Ru}^{\mathrm{II}}{ }^{48}$

In addition to their emissive properties, metal ions also offer the possibility of electrochemical read out. Beer and co-workers have demonstrated this using ferrocene substituted MIMs in which anion binding perturbs the $\mathrm{Fe}^{\mathrm{II} / \mathrm{III}}$ couple leading to a cathodic shift (Fig. 17). ${ }^{49}$ Extending this to Os ${ }^{\mathrm{III}}$, as in rotaxane 34,

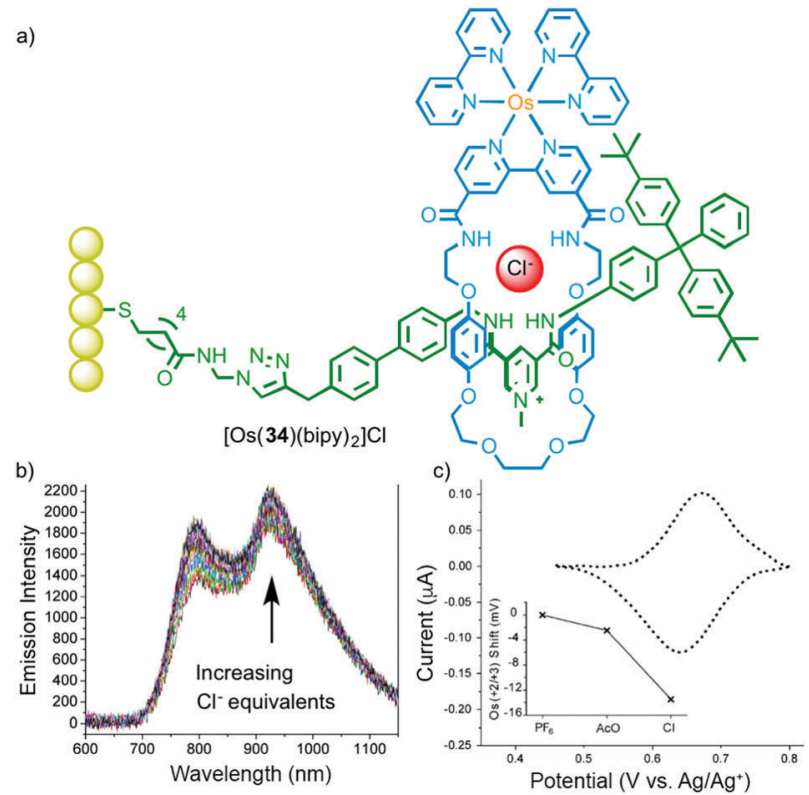

Fig. 17 (a) Surface appended electrochemical anion sensor [Os(34)(bipy) $\left.{ }_{2}\right]$ with bound chloride anion and (b) its optical and (c) electrochemical response to $\mathrm{Cl}^{50}$ Adapted with permission from ref. 50. Copyright 2013 WILEY-VCH Verlag GmbH \& Co. KGaA, Weinheim.
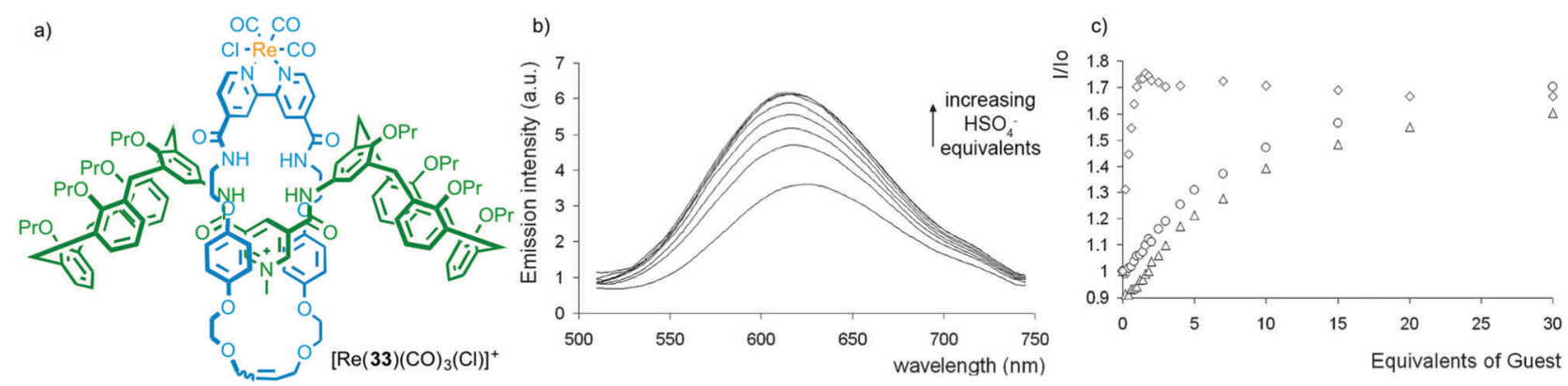

Fig. 16 (a) Beer's hydrogen bonding host $\left[\operatorname{Re}(33)(\mathrm{CO})_{3}(\mathrm{Cl})\right]^{+}$, (b) its optical read out on $\mathrm{HSO}_{4}{ }^{-}$addition and (c) a comparison with the response of the rotaxane host (diamonds), the corresponding non-interlocked macrocycle (triangles) and an acyclic analogue (circles). ${ }^{44}$ Reproduced from ref. 44 with permission from the Royal Society of Chemistry. 
and mounting the host on a gold surface allowed the anion binding event to be detected both optically and electrochemically. ${ }^{50}$

The examples presented above clearly show that metal ions bound within the MIM structure can be used to report changes upon guest binding which, combined with the selectivity imparted by the mechanical bond, provide an excellent platform for sensor development.

\section{Mechanically interlocked ligands in metallo-supramolecular chemistry}

There is currently a growing interest in metallo-supramolecular materials in which metal-ligand interactions are used to direct the assembly of complex 1D, 2D and 3D architectures. ${ }^{51}$ In the final section of this Feature Article we will discuss systems that attempt to combine MILs with metallo-supramolecular assembly. We have chosen to focus on robust, permanently interlocked building blocks rather than metallo-supramolecular systems based on pseudorotaxane units in which the metalligand interactions are integral to the stability of the interlocked structure. $^{52}$

\section{Discrete metallo-supramolecular assemblies}

As a first step towards metallo-supramolecular assemblies, in 2003 Loeb and co-workers demonstrated the homo-dimerisation of rotaxane ligand $35^{3+}$, which is functionalised by a terpyridine stopper unit, to give a simple MIM-based metal complex. Treatment with $\mathrm{Fe}^{\mathrm{II}}$ led to a homoleptic low-spin $\mathrm{Fe}^{\mathrm{II}}$ complex in which two rotaxane ligands bind to the $\mathrm{Fe}$ centre and the resulting complex was characterised by ${ }^{1} \mathrm{H}$ NMR, MS and UVvis spectroscopy (Fig. 18). ${ }^{53}$ What is perhaps noteworthy about this relatively simple coordination complex is that, by associating the axle units using metal-ligand interactions, the macrocycle components are also brought into proximity. Crowley and co-workers demonstrated the inverse of this effect by substituting the macrocycle component of a [2]rotaxane with terpyridine moieties. $^{54}$
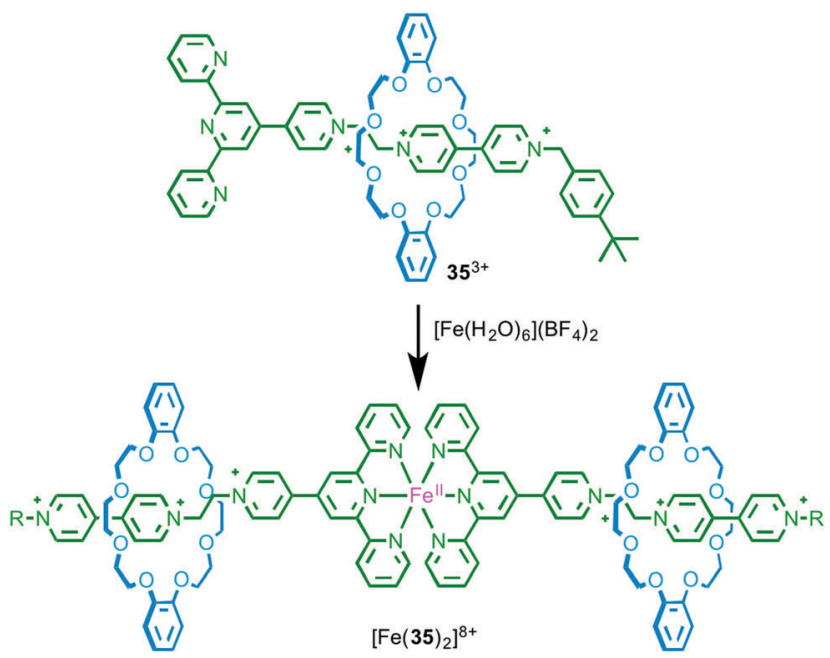

Fig. 18 Dimerisation of rotaxane ligand $35^{3+}$ in the presence of Fe ${ }^{11} .53$

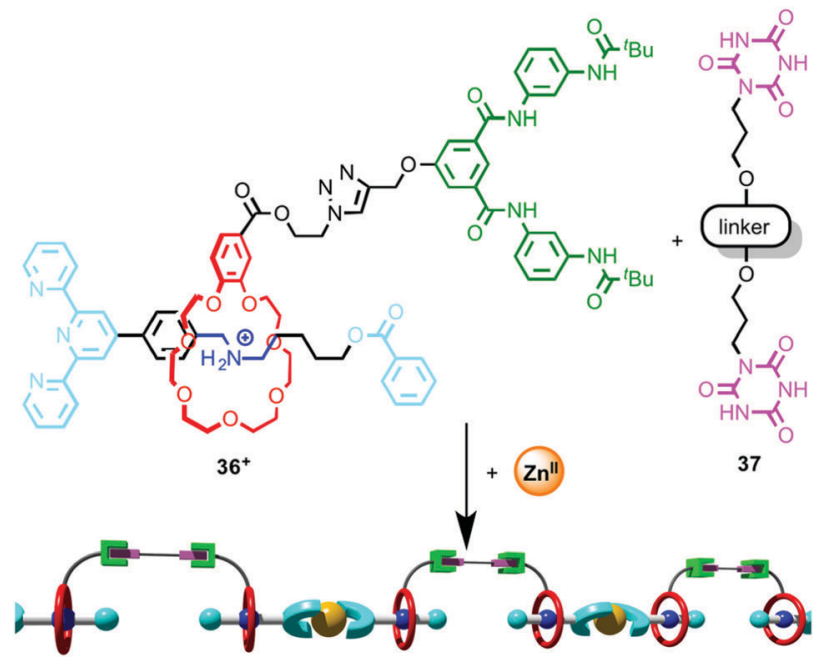

Fig. 19 Hierarchical self-assembly of a metallo-supramolecular dimer. ${ }^{55}$

Wang and co-workers took advantage of such a coordinationdriven dimerisation of [2]rotaxane ligands to construct supramolecular polymers using hierarchical self-assembly. ${ }^{55}$ Monomer unit [2] rotaxane $\mathbf{3 6}$ is stoppered by a terpyridine moiety and the macrocycle is substituted with a Hamilton receptor (Fig. 19). Addition of $\mathrm{Zn}^{\mathrm{II}}$ leads to the efficient dimerisation of the rotaxane ligand, which produces an assembly containing two Hamilton receptors. At concentrations above $\sim 7 \mathrm{mM}$, this dimer selfassembles through $\mathrm{H}$-bonding interactions in the presence of bis-cyanuric acid derivative 37 to produce a supramolecular polymer, and the polymerisation process was monitored by DOSY NMR and viscometry. Importantly, neither $\mathrm{Zn}^{\mathrm{II}}$ nor biscyanuric acid derivative $\mathbf{3 7}$ alone are sufficient for supramolecular polymerisation to take place. The product polymer forms flexible, transparent free-standing films.

In the case of the examples above either the axle or macrocycle component provide the ligand used in the assembly of the metallo-dimer and the only effect of the mechanical bond is to associate the second covalent component with the assembly. In 2014 Crowley and co-workers observed a dimeric complex in which both the macrocycle and thread provide donor atoms (Fig. 20). In the presence of $\mathrm{Ag}^{\mathrm{I}}$ ions, [2] rotaxane 38 dimerised to form an $\mathrm{M}_{2} \mathrm{~L}_{2}$ assembly; in the solid state the silver ions adopted a distorted trigonal planar geometry, with the 1,2,3triazole units of the thread acting as bridging ligands between

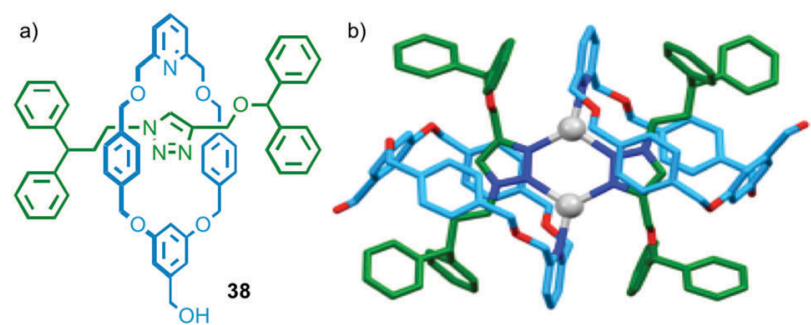

Fig. 20 (a) Interlocked rotaxane ligands $\mathbf{3 8}$ and (b) the solid state structure of the corresponding dimer formed in the presence of $\mathrm{Ag}^{156}$ 
two $\mathrm{Ag}^{\mathrm{I}}$ ions (forming a six membered metallocycle), and the pyridines of the macrocycle completing the coordination sphere (Fig. 20b). ${ }^{56}$

Schalley and co-workers recently extended this approach to surface modification by using a $\mathrm{Pd}^{\mathrm{II}}$ ion to link rotaxane 39 to a gold surface and study the ordering of the interlocked molecule at the interface (Fig. 21a). ${ }^{57}$ The terpyridine ligand of rotaxane 39 was first coordinated to $\mathrm{Pd}^{\mathrm{II}}$ to give a stable complex with a labile coordination site. A monolayer was prepared functionalised by a linear mono-pyridine ligand. Immersion of this monolayer in a solution of $[\mathrm{Pd}(39)(\mathrm{MeCN})]$ resulted in coordination to the monopyridine ligands, generating an ordered array of rotaxanes bound to the gold surface. X-ray photoelectron

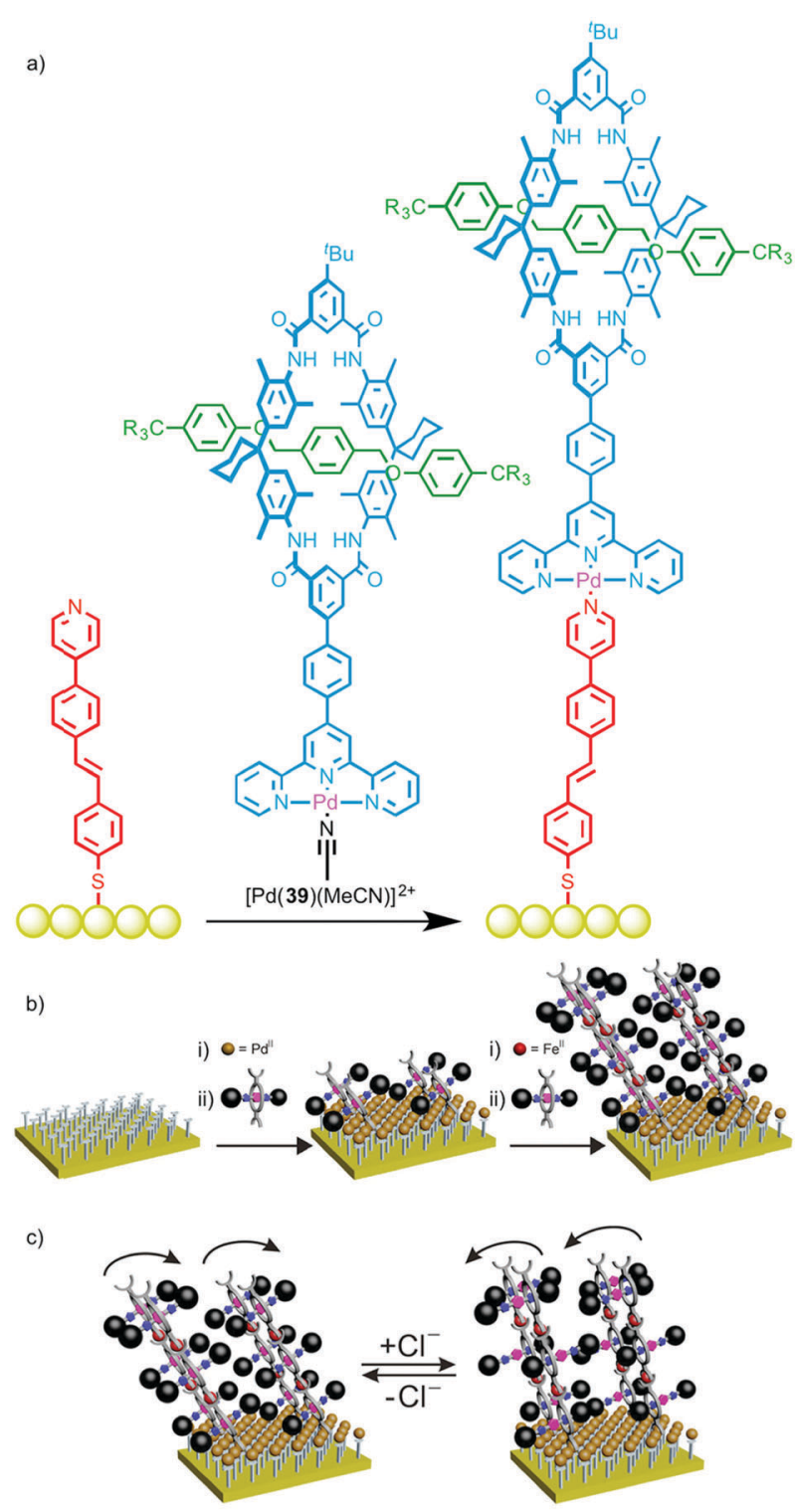

Fig. 21 (a) Schalley's rotaxane monolayer assembled using metallosupramolecular chemistry; ${ }^{57}$ (b) a cartoon representation of the layer-by-layer deposition of $\mathrm{Cl}$-responsive rotaxanes and (c) their proposed switching in the presence of $\mathrm{Cl}$ anions. ${ }^{58}$ Adapted with permission from ref. 58 . Copyright 2015 American Chemical Society.

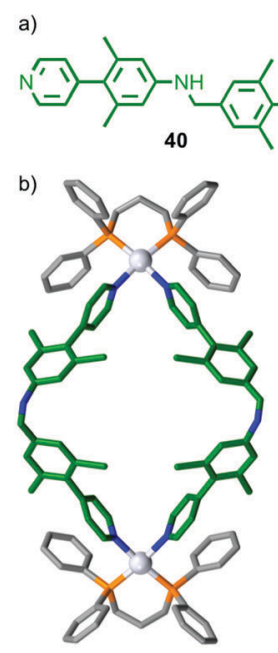

$\left[\mathrm{Pt}_{2}(\mathbf{4 0})_{2}(\mathrm{dppp})_{2}\right]^{4+}$
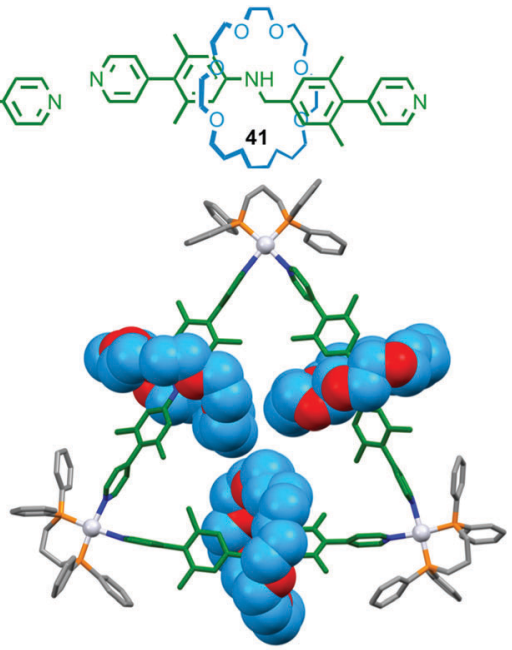

$\left[\mathrm{Pt}_{3}(41)_{3}(\mathrm{dppp})_{3}\right]^{6+}$
Fig. 22 (a) Rotaxane $\mathbf{4 1}$ and corresponding non-interlocked axle $\mathbf{4 0}$ and (b) the products of their self-assembly in the presence of $\mathrm{Pt}$.11.

spectroscopy (XPS) confirmed the presence of the iodine-labeled rotaxane axle on the surface, with near-edge X-ray absorption fine structure (NEXAFS) spectroscopy revealing nitrogen resonances indicative of the macrocycle, thus leading to the conclusion that the rotaxanes had been successfully bound to the surface. A linear dichroism effect was observed in the NEXAFS C K-edge, suggesting the formation of ordered arrays of the surface-bound rotaxanes, and a packing density of $15-20 \%$ was estimated from XPS data.

This self-assembly technique was subsequently employed to deposit multilayers of a chloride-responsive rotaxane in which the macrocycle was substituted with two terpyridine moieties (Fig. 21b). ${ }^{58}$ This allowed the layer-by-layer deposition by sequentially washing the surface with solutions of $\mathrm{Fe}\left(\mathrm{BF}_{4}\right)_{2} \cdot 6 \mathrm{H}_{2} \mathrm{O}$ and the rotaxane, with addition of up to 20 layers reported. Most impressively, the surface-bound rotaxane multilayer retained its ability to bind chloride ions; reversible changes in contact angle measurements and angle-resolved NEXAFS spectra upon addition and removal of chloride ions suggested on-surface switching took place (Fig. 21c).

Although there is increasing interest in the use of MIMs in metallo-supramolecular assembly, relatively little attention has been paid to the effect of the mechanical bond on the outcome of the assembly process. Loeb has recently found that bispyridine ligand $\mathbf{4 0}$ and its interlocked analogue $\mathbf{4 1}$ form different architectures in the presence of $\mathrm{Pt}^{\mathrm{II}}$ (dppp) (Fig. 22); ${ }^{59}$ non-interlocked axle $\mathbf{4 0}$ formed a simple $\mathrm{M}_{2} \mathrm{~L}_{2}$ metallo-rectangle whereas [2] rotaxane 41 formed a $\mathrm{M}_{3} \mathrm{~L}_{3}$ molecular necklace and higher order $\mathrm{M}_{n} \mathrm{~L}_{n}$ complexes. The difference in behaviour between rotaxane $\mathbf{4 1}$ and axle $\mathbf{4 0}$ was attributed to the higher rigidity of the interlocked ligand induced by the encircling macrocycle, combined with the increased steric demand provided by the macrocycle; the macrocycles completely fill the cavity of the triangle.

\section{Interlocked metallo-supramolecular polymers}

The discrete assemblies above, in particular Loeb's molecular triangle, suggest the possibility of larger metallo-polymers. ${ }^{60}$ 
a)
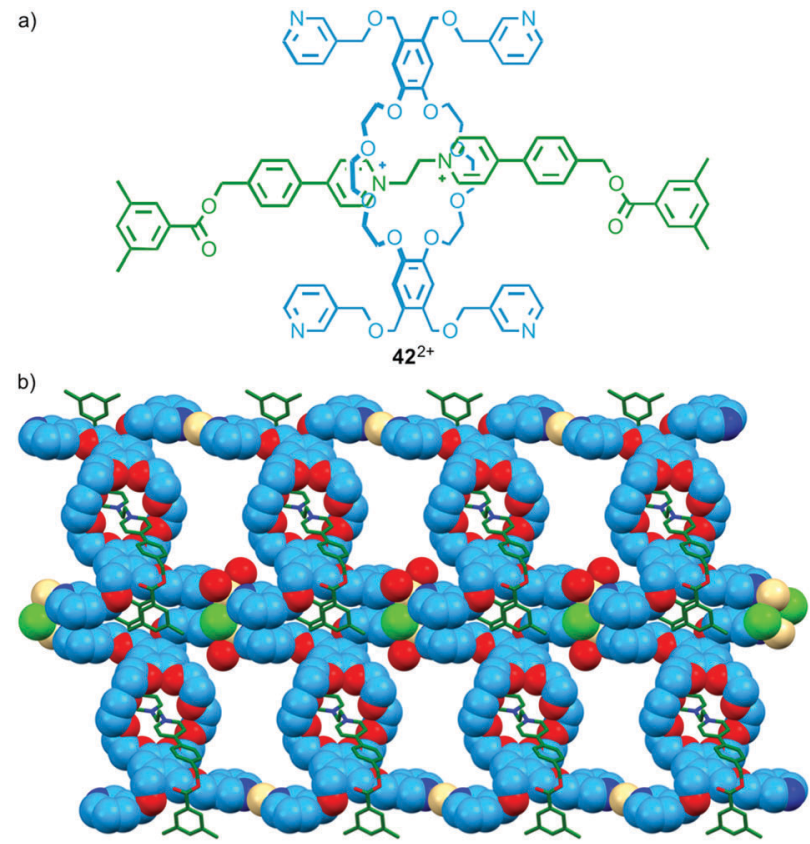

Fig. 23 (a) Tetradentate interlocked ligand $\mathbf{4 2}^{2+}$ and (b) the product of its self-assembly in the presence of $\mathrm{Cd}^{\prime \prime}{ }^{61}$

The first such structure based on a permanently interlocked [2]rotaxane linker relied on ligands not in the axle component but in the macrocycle. ${ }^{61}$ In 2011 Loeb and co-workers reported a series of rotaxanes in which the macrocycle component was appended with pyridine-based ligands. When rotaxane $\mathbf{4 2}$, in which each macrocycle bears four 3 -substituted pyridine units (Fig. 23a), was combined with $\mathrm{Cd}^{\mathrm{II}}$ a coordination polymer was obtained in which the pyridine ligands of each macrocycle coordinate to a different $\mathrm{Cd}^{\mathrm{II}}$ ion (Fig. 23b). The authors later extended the approach by replacing the pyridine ligands with thio-ether units to create coordination polymers using $\mathrm{Ag}^{\mathrm{I}}-\mathrm{S}$ interactions. $^{62}$

Through post-synthetic modification of a [2]rotaxane, Crowley and co-workers were able to install terpyridine units on both the macrocycle and thread components (Fig. 24) ${ }^{54}$ Addition of $\left[\mathrm{Fe}\left(\mathrm{H}_{2} \mathrm{O}\right)_{6}\right]\left(\mathrm{BF}_{4}\right)_{2}$ to a dilute solution of functionalised rotaxane

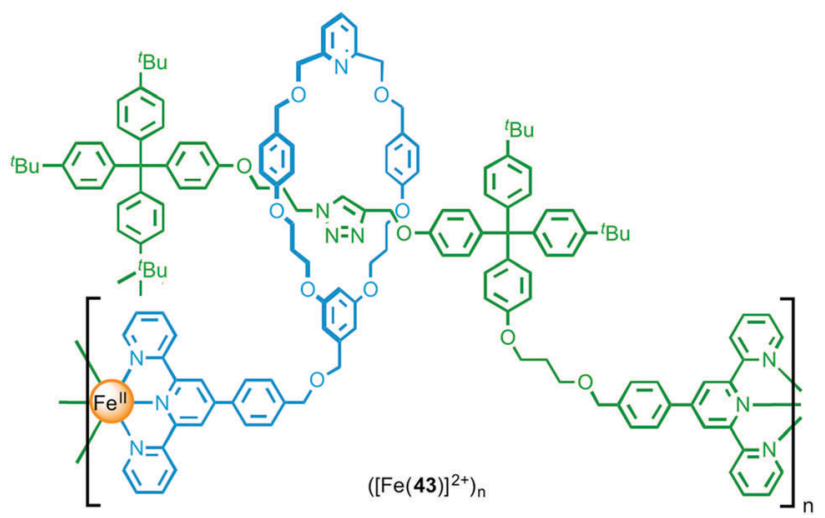

Fig. 24 A metallo-supramolecular polymer formed by coordination of Fe" to both the macrocycle and the axle.

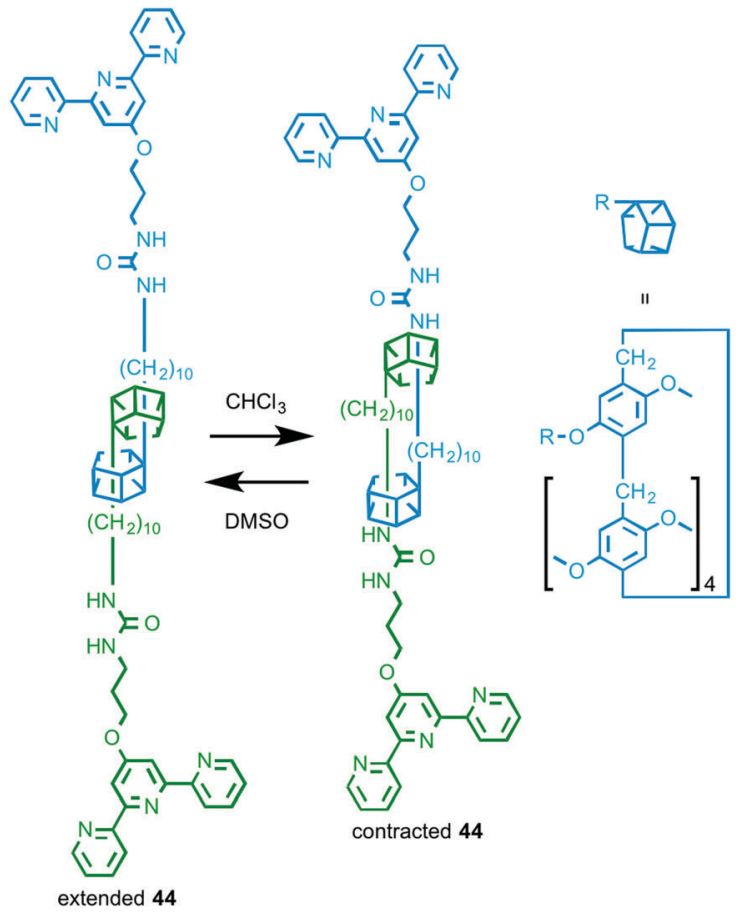

Fig. 25 Solvent responsive monomer $\mathbf{4 4}$ that assembles in the presence of $\mathrm{Fe}^{11}$ to give a stimuli-responsive metallo-supramolecular polymer. ${ }^{63}$

43 resulted in formation of a simple ML complex, with coordination of the macrocyclic and thread terpyridine units from the same rotaxane to an $\mathrm{Fe}^{\mathrm{II}}$ ion. Conversely, addition of $\mathrm{FeCl}_{2}$ to a concentrated solution of the rotaxane yielded metallo-oligomeric species, underlining the important role that the reaction conditions play in determining the outcome of coordination-based polymerisation reactions. Using both DOSY NMR and GPC the metallo-oligomers were estimated to be formed from between 11 and 13 rotaxane units.

In 2014 Huang and co-workers reported a rotaxane molecular machine-based metallo-supramolecular polymer. ${ }^{63}$ Rotaxane $\mathbf{4 4}$ (Fig. 25) is based on their previously reported "molecular spring" in which changing the solvent environment changes the preferred positions of the macrocycles on the axle, resulting in a change in the average length of the assembly. ${ }^{64}$ In the presence of $\mathrm{FeCl}_{2}, \mathbf{4 4}$ assembles into a 1D supramolecular polymer and the resulting fibres were visualised by TEM and SEM. As with the monomeric building block 44 (Fig. 25), variation in the solvent environment changes the length of the assembled metallo-supramolecular polymer and these changes were visualised using DLS.

\section{Metal-organic frameworks (MOFs)}

Crystalline coordination polymers in which the network contains appreciable void space - commonly referred to as metal organic frameworks (MOFs) - have become an intense area of research for applications as diverse as drug delivery, gas sorption, sorting of chemical mixtures ${ }^{65}$ and recently as an analytic tool in X-ray crystallography. ${ }^{66}$ In recent years several research groups have sought to combine MOFs and MIMs to generate networks with interlocked ligand components. 

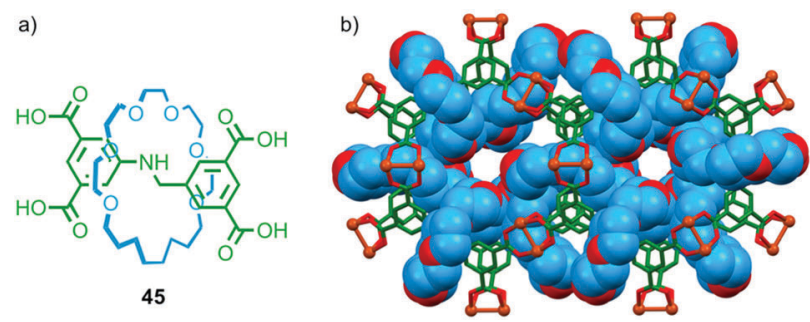

Fig. 26 (a) Tetracarboxylic acid ligand rotaxane $\mathbf{4 5}$ and (b) the MOF formed by $\mathbf{4 5}$ in the presence of $\mathrm{Cu}^{11} .67$

Loeb and co-workers have demonstrated a number of crown ether-ammonium templated rotaxanes as MOF building blocks. In 2012 they reported that tetra-carboxylic acid rotaxane $\mathbf{4 5}$ formed a crystalline MOF when heated with $\mathrm{Cu}\left(\mathrm{NO}_{3}\right)_{2} \cdot 3 \mathrm{H}_{2} \mathrm{O}$ in DMF-EtOH- $\mathrm{H}_{2} \mathrm{O}$ and allowed to cool slowly (Fig. 26). ${ }^{67}$ Single crystal X-ray analysis confirmed the porous nature of UWDM-1 and revealed that the crown ether macrocycle is hydrogen bonded to a water molecule bound to a $\mathrm{Cu}^{\mathrm{II}}$ paddle-wheel unit (Fig. 26b). This interaction, combined with steric interactions with further molecules of $\mathrm{H}_{2} \mathrm{O}$ occupying void space in the lattice, lock the macrocycle in place, preventing free rotation of the macrocycle relative to the lattice.

Heating the green, as-synthesised material to $150{ }^{\circ} \mathrm{C}$ in vacuo removed these water molecules. In the new lattice the macrocycle components are significantly less restricted and a number of dynamic modes were observed including pirouetting of the ring around the axle. This activation was reversible and the material could be switched between rotating and locked states repeatedly. The rotation of the macrocycles around the struts of the framework could be monitored by variable temperature solid-state ${ }^{13} \mathrm{C}$ and ${ }^{2} \mathrm{H}$ NMR (of a labelled analogue), which showed the barrier to be around $50 \mathrm{~kJ} \mathrm{~mol}^{-1}$.

In later work Loeb and co-workers investigated the effect of macrocycle structure on the solid-state dynamics of a family of related MOFs. ${ }^{68}$ Replacing the 24 membered crown ether with a 22-membered analogue resulted in a framework that does not display macrocycle rotation in the solid state, which was attributed to the enhanced hydrogen bonding interaction between the smaller ring and the aniline proton. Similarly, when a bulkier 24-membered crown ether was investigated, free rotation was not observed, presumably due to the increased steric barrier. This study suggests that the solid-state dynamics of such systems can be tuned rationally.

Having demonstrated the pirouetting of the macrocycle of a rotaxane within a MOF framework Loeb and co-workers turned their attention to the issue of macrocycle shuttling in the solid state. ${ }^{69}$ Molecular shuttle $\mathbf{4 6}$ with two degenerate benzimidazole stations was prepared, with $50 \%$ of the stations labelled using ${ }^{13} \mathrm{C}$ at the central imidazole carbon (Fig. 27a). Solution phase studies demonstrated that the chemical shift of the ${ }^{13} \mathrm{C}$ labelled imidazole station varies depending on whether it is encircled by the macrocycle or not $\left(46^{-13} \mathrm{C}\right.$-occupied or $46^{-12} \mathrm{C}$-occupied respectively). Ligand 46 assembled in the presence of $\mathrm{Zn}^{\mathrm{II}}$ to form a porous MOF (Fig. 27b). Using line shape analysis, solid state

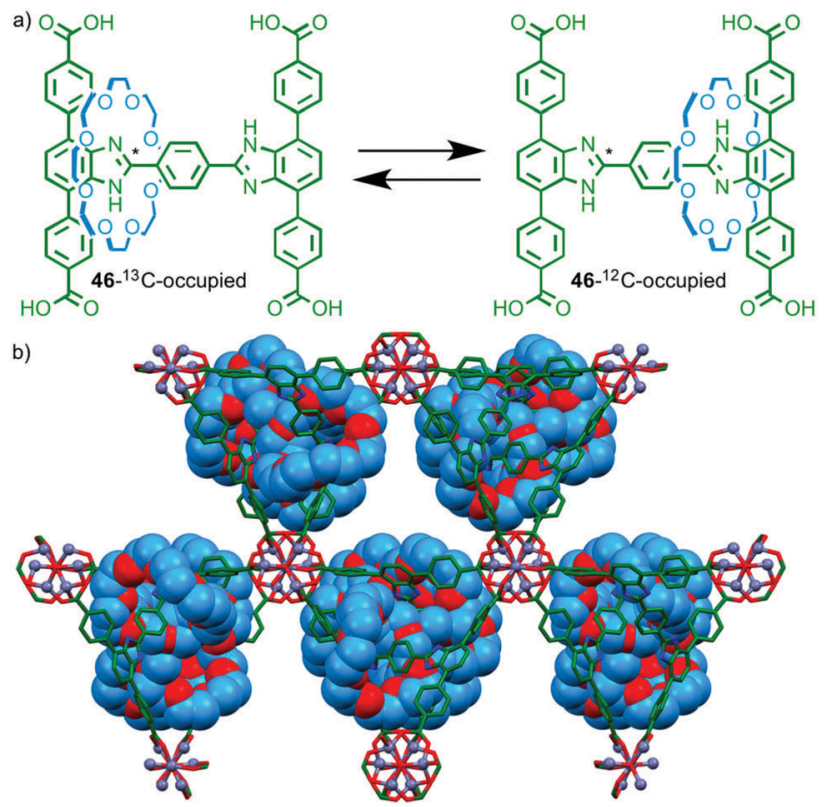

Fig. 27 (a) Pseudo-degenerate molecular shuttle 46 and (b) the MOF formed by reaction of $\mathbf{4 6}$ with $\mathrm{Zn}$ ". Solid state ${ }^{13} \mathrm{C}$ NMR line shape analysis revealed that the macrocycle continues to shuttle even in the solid state. ${ }^{64}$

${ }^{13} \mathrm{C}$ NMR allowed rate constants to be determined for the shuttling motion in the MOF framework and the macrocycle was shown to be in dynamic exchange even at room temperature. Unsurprisingly given the crowded nature of the solid-state structure, the rate of shuttling in the rotaxane MOF framework was five orders of magnitude lower than in solution.

Stoddart, Yaghi and co-workers have investigated the synthesis of catenane-based coordination polymers. Catenanes $\mathbf{4 7 ^ { \mathbf { 4 } }}$, which were assembled using donor-acceptor $\pi-\pi$ interactions, contain a rigid strut appended by carboxylate groups, common ligands in the assembly of metallo-supramolecular polymers (Fig. 28a). The length of the strut was found to be crucial to the metallo-supramolecular structure formed in the presence of $\mathrm{Cu}^{\mathrm{I}}$; both ligands gave the same coordination mode about the metal ions but the smaller $(19.3 \AA)$ strut length $\left(\mathbf{4 7 \mathbf { a } ^ { 4 + } )}\right.$ gave a $2 \mathrm{D}$ coordination network, ${ }^{70}$ whilst the larger (32.9 $\mathrm{A})$ strut $\left(\mathbf{4 7 b}^{\mathbf{4}}\right)$ resulted in a 3D MOF (Fig. 28b). ${ }^{71}$ a)

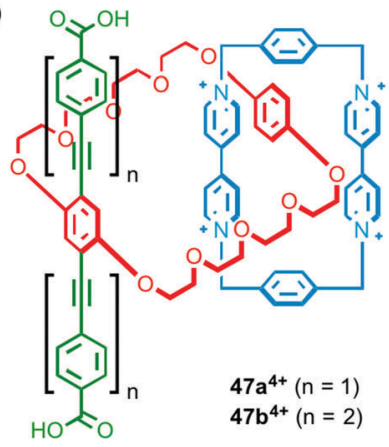

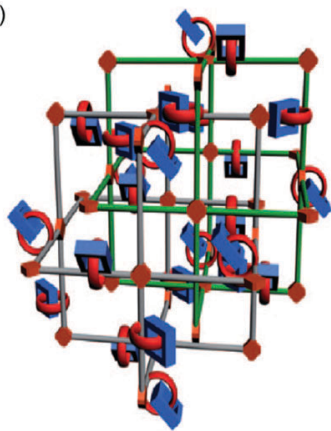

Fig. 28 (a) Catenanes $47^{4+}$ with different length strut units and (b) a cartoon representation of the MOF formed by $\mathbf{4 7 b ^ { 4 + }}$ in the presence of $\mathrm{Cu}^{\prime}{ }^{71}$ Adapted with permission from ref. 71. Copyright 2010 WILEY-VCH Verlag GmbH \& Co. KGaA, Weinheim. 
Combining metallo-supramolecular chemistry with MIMs is a relatively new area that holds promise in the development of functional materials by providing new structural motifs, combining the benefits of supramolecular polymerisation and stimuli responsive behaviour and, particularly in the case of MOFs, offering the possibility of dynamic behaviour in systems that are typically required to be rigid to maintain porosity and stability; Loeb's recent contributions regarding large amplitude motion of the macrocycle component in the solid state clearly demonstrate this principle of "robust dynamics". $52 c$ By providing a new approach to interfacing the behaviour of molecular machines with the macroscopic world, metallo-supramolecular chemistry brings real-world applications of these intriguing molecules one step closer.

\section{Conclusions and outlook}

The exploitation of MIMs as ligands has a long history given the central role metal-ligand interactions have played in the synthesis of rotaxanes and catenanes. However, the application of such metal complexes, beyond the operation of molecular machines, is a relatively recent phenomenon. In this Feature Article we have highlighted some of the under-exploited areas that we believe MIMs have the potential to have an impact in. In particular, the ability of the interlocked structure to augment the properties of the bound metal ion in terms of the kinetic and thermodynamic stability of the metal complex and its catalytic activity have only received relatively cursory attention to date. For the potential of these systems to be realised it is important that, wherever possible, relevant comparisons with a corresponding noninterlocked ligand are performed. Similarly, the use of interlocked molecules as scaffolds for metal ion sensing is currently underdeveloped, despite the success of interlocked molecules for sensing other charged species. Again, simple tests of metal ion selectivity need to be performed routinely.

In both sensing and catalysis, systems that take advantage of the potential for unusual stereoisomerism in interlocked structures have yet to be reported. ${ }^{72}$ This arguably represents a significant and untapped area for study; the ability to rapidly generate chiral, crowded but flexible chemical fields for sensing or catalysis could bring benefits in sensing of chiral analytes and enantioselective catalysts. ${ }^{73}$

The area that has shown the greatest development recently is that of metallo-supramolecular materials but it is clear that there is still much to discover; the first rotaxane shuttle in a metal organic framework was only reported very recently. The potential to combine metallo-supramolecular assembly with some of the other areas we have highlighted to produce, for example, frameworks that selectively sequester metal ions for extraction, metallo-supramolecular supports for heterogeneous interlocked catalysts and sensors, and stimuli responsive frameworks with dynamic properties, present exciting opportunities for further study.

As more details emerge of the potential benefits of ligand frameworks based on rotaxanes and catenanes in a variety of areas, it seems likely that the field will expand rapidly. Based on the results presented in this Feature article we have no doubt that mechanically interlocked molecules have a bright future as ligands for a range of applications.

\section{Acknowledgements}

We thank the University of Southampton, EPSRC (EP/L016621/1) and Royal Society for financial support. J. E. M. L. is an EU Marie Skłodowska-Curie Fellow, receiving financial support from the European Union's Horizon 2020 research and innovation programme under Marie Sklodowska-Curie grant agreement No. 660731. M. G. thanks the EPRSC for a Doctoral Prize. S. M. G. is a Royal Society Research Fellow.

\section{Notes and references}

1 For selected recent reviews on the synthesis and applications of MIMs see: (a) J. E. Beves, B. A. Blight, C. J. Campbell, D. A. Leigh and R. T. McBurney, Angew. Chem., Int. Ed., 2011, 50, 9260; (b) A. Coskun, M. Banaszak, R. D. Astumian, J. F. Stoddart and B. A. Grzybowski, Chem. Soc. Rev., 2012, 41, 19; (c) N. H. Evans and P. D. Beer, Chem. Soc. Rev., 2014, 43, 4658; (d) E. A. Neal and S. M. Goldup, Chem. Commun., 2014, 50, 5128; (e) S. Erbas-Cakmak, D. A. Leigh, C. T. McTernan and A. L. Nussbaumer, Chem. Rev., 2015, 115, 10081; (f) M. Xue, Y. Yang, X. Chi, X. Yan and F. Huang, Chem. Rev., 2015, $115,7398$.

2 C. O. Dietrich-Buchecker, J.-P. Sauvage and J. P. Kintzinger, Tetrahedron Lett., 1983, 24, 5095; C. O. Dietrich-Buchecker, J.-P. Sauvage and J. M. Kern, J. Am. Chem. Soc., 1984, 106, 3043.

3 We refer to methods in which metal-ligand interactions simply assemble the MIM precursors and those in which the metal ion also mediates the reaction that captures the interlocked structure as "passive" and "active" respectively: J. D. Crowley, S. M. Goldup, A.-L. Lee, D. A. Leigh and R. T. McBurney, Chem. Soc. Rev., 2009, 38, 1530.

4 C. Wu, P. R. Lecavalier, Y. X. Shen and H. W. Gibson, Chem. Mater., 1991, 3, 569.

5 A. M. Albrecht-Gary, Z. Saad, C. O. Dietrich-Buchecker and J. P. Sauvage, J. Am. Chem. Soc., 1985, 107, 3205.

6 The kinetic stabilisation of chelated metal complexes and complexes of cryptand ligands are known as the chelate and cryptate effects respectively (Pure Appl. Chem. 1977, 49, 857). However, when Sauvage and co-workers observed the kinetic stabilisation of metal complexes of catenane ligands (also known as catenands) they named this the "catenand effect", presumably to avoid confusion with the existing verb "to catenate", meaning to arrange atoms in a chain.

7 D. H. Busch, Chem. Rev., 1993, 93, 847.

8 C. Dietrich-Buchecker, J.-P. Sauvage and J.-M. Kern, J. Am. Chem. Soc., 1989, 111, 7791.

9 A. J. Blake, C. O. Dietrich-Buchecker, T. I. Hyde, J.-P. Sauvage and M. Schröder, J. Chem. Soc., Chem. Commun., 1989, 1663.

10 C. O. Dietrich-Buchecker, J.-M. Kern and J.-P. Sauvage, J. Chem. Soc., Chem. Commun., 1985, 760.

11 D. A. Leigh, P. J. Lusby, A. M. Z. Slawin and D. B. Walker, Angew. Chem., Int. Ed., 2005, 44, 4557.

12 V. Aucagne, K. D. Hänni, D. A. Leigh, P. J. Lusby and D. B. Walker, J. Am. Chem. Soc., 2006, 128, 2186.

13 H. Lahlali, K. Jobe, M. Watkinson and S. M. Goldup, Angew. Chem., Int. Ed., 2011, 50, 4151.

14 J. Winn, A. Pinczewska and S. M. Goldup, J. Am. Chem. Soc., 2013, 135, 13318.

15 For a recent example that showcases the flexibility of MILs: G. Baggi and S. J. Loeb, Angew. Chem., Int. Ed., 2016, 55, 12533.

16 Z. Kelman and M. O'Donnell, Annu. Rev. Biochem., 1996, 64, 171.

17 (a) P. Thordarson, E. J. A. Bijsterveld, A. E. Rowan and R. J. M. Nolte, Nature, 2003, 424, 915; (b) P. H. Ramos, R. G. E. Coumans, A. B. C. Deutman, J. M. M. Smits, R. de Gelder, J. A. A. W. Elemans, 
R. J. M. Nolte and A. E. Rowan, J. Am. Chem. Soc., 2007, 129, 5699; (c) R. G. E. Coumans, J. A. A. W. Elemans, R. J. M. Nolte and A. E. Rowan, Proc. Natl. Acad. Sci. U. S. A., 2006, 103, 19647.

18 S. F. M. van Dongen, J. Clerx, K. Nørgaard, T. G. Bloemberg, J. J. L. M. Cornelissen, M. a. Trakselis, S. W. Nelson, S. J. Benkovic, A. E. Rowan and R. J. M. Nolte, Nat. Chem., 2013, 5, 945.

19 N. Miyagawa, M. Watanabe, T. Matsuyama, Y. Koyama, T. Moriuchi, T. Hirao, Y. Furusho and T. Takata, Chem. Commun., 2010, 46, 1920.

20 For a related study on the effect of macrocycle size on the efficiency of such macrocyclic Pd complexes see: M. Ogawa, M. Nagashima, H. Sogawa, S. Kuwata and T. Takata, Org. Lett., 2015, 17, 1664.

21 Y. Matsuoka, Y. Mutoh, I. Azumaya, S. Kikkawa, T. Kasama and S. Saito, J. Org. Chem., 2016, 81, 3479.

22 B. Lewandowski, G. De Bo, J. W. Ward, M. Papmeyer, S. Kuschel, M. J. Aldegunde, P. M. E. Gramlich, D. Heckmann, S. M. Goldup, D. M. D'Souza, A. E. Fernandes and D. A. Leigh, Science, 2013, 339, 189; G. De Bo, S. Kuschel, D. A. Leigh, B. Lewandowski, M. Papmeyer and J. W. Ward, J. Am. Chem. Soc., 2014, 136, 5811.

23 For examples in non-metal based systems see: (a) A. H. Parham, B. Windisch and F. Vögtle, Eur. J. Org. Chem., 1999, 1233; (b) N. Kihara, Y. Tachibana, H. Kawasaki and T. Takata, Chem. Lett., 2000, 506; (c) T. Oku, Y. Furusho and T. Takata, Org. Lett., 2003, 5, 12384; (d) C. B. Caputo, K. Zhu, V. N. Vukotic, S. J. Loeb and D. W. Stephan, Angew. Chem., Int. Ed., 2013, 52, 960; (e) A. Martinez-Cuezva, C. LopezLeonardo, D. Bautista, M. Alajarin and J. Berna, J. Am. Chem. Soc., 2016, 138, 8726.

24 M. Yamazaki, T. Hagiwara, M. Sekiguchi, T. Sawaguchi and S. Yano, Synth. Commun., 2008, 38, 553.

25 Y. Suzaki, K. Shimada, E. Chihara, T. Saito, Y. Tsuchido and K. Osakada, Org. Lett., 2011, 13, 3774.

26 For an example of a related approach to developing bimetallic hosts for flexible guests see: J. Frey, C. Tock, J. P. Collin, V. Heitz and J. P. Sauvage, J. Am. Chem. Soc., 2008, 130, 4592.

27 S. Hoekman, M. O. Kitching, D. A. Leigh, M. Papmeyer and D. Roke, J. Am. Chem. Soc., 2015, 137, 7656.

28 M. Galli, J. E. M. Lewis and S. M. Goldup, Angew. Chem., Int. Ed., 2015, 54, 13545.

29 A. Poater, B. Cosenza, A. Correa, S. Giudice, F. Ragone, V. Scarano and L. Cavallo, Eur. J. Inorg. Chem., 2009, 1759.

30 A. Poater, B. Cosenza, A. Correa, S. Giudice, F. Ragone, V. Scarano and L. Cavallo, Eur. J. Inorg. Chem., 2009, 1759.

31 Macrocyclic ligands have been shown to display enhanced stereoselectivity compared with their acyclic analogues: T. Portada, M. Roje, Z. Raza, V. Čaplar, M. Žinić and V. Šunjić, Eur. J. Org. Chem., 2007, 838.

32 For selected examples and reviews of sensors based on interlocked molecules see: $(a)$ N. Kameta, Y. Nagawa, M. Karikomi and K. Hiratani, Chem. Commun., 2006, 3714; (b) J. J. Gassensmith, S. Matthys, J. J. Lee, A. Wojcik, P. V. Kamat and B. D. Smith, Chem. - Eur. J., 2010, 16, 2916; (c) W. Wong, K. C.-F. Leung and J. F. Stoddart, Org. Biomol. Chem., 2010, 8, 2332; (d) J. J. Gassensmith, S. Matthys, J. J. Lee, A. Wojcik, P. V. Kamat and B. D. Smith, Chem. Eur. J., 2010, 16, 2916; (e) X. Ma and H. Tian, Chem. Soc. Rev., 2010, 39, 70; $(f)$ M. J. Langton and P. D. Beer, Acc. Chem. Res., 2014, 47, 1935; $(g)$ M. J. Langton, I. Marques, S. W. Robinson, V. Félix and P. D. Beer, Chem. - Eur. J., 2016, 22, 185; (h) R. Mitra, M. Thiele, F. Octa-Smolin, M. C. Letzel and J. Niemeyer, Chem. Commun., 2016, 52, 5977.

33 (a) M. J. MacLachlan, A. Rose and T. M. Swager, J. Am. Chem. Soc., 2001, 123, 9180; (b) S. S. Zhu, P. J. Carroll and T. M. Swager, J. Am. Chem. Soc., 1996, 118, 8713; (c) P. H. Kwan and T. M. Swager, J. Am. Chem. Soc., 2005, 127, 5902 .

34 For a related system in which metal binding controls electron transfer between $\mathrm{Zn}$ and $\mathrm{Au}$ porphyrins see: J. C. Chambron, A. Harriman, V. Heitz and J. P. Sauvage, J. Am. Chem. Soc., 1993, 115, 7419.

35 Y. Nakatani, Y. Furusho and E. Yashima, Angew. Chem., Int. Ed., 2010, 49, 5463.

36 The role of the $\mathrm{Zn}^{2+}$ ion may be to coordinate to the carboxylate or the amidine moiety. However, the authors provide evidence that amidine coordination is preferred and we have adopted their representation here. ${ }^{35}$.

37 Arguably, structures such as $\mathbf{3 0}$ are not mechanically interlocked because the macrocycle and axle components are covalently linked. However, they are commonly referred to as [1] rotaxanes, where "[1]" refers to the single covalent component present, and we follow this convention here. For more information on nomenclature see: A. Yerin, E. S. Wilks, G. P. Moss and A. Harada, Pure Appl. Chem., $2008,80,2041$.

38 K. Hiratani, M. Kaneyama, Y. Nagawa, E. Koyama and M. Kanesato, J. Am. Chem. Soc., 2004, 126, 13568.

39 For an example of the selective discrimination of alkali metal ions by a rotaxane host using ${ }^{1} \mathrm{H}$ NMR see: N.-C. Chen, P.-Y. Huang, C.-C. Lai, Y.-H. Liu, Y. Wang, S.-M. Peng and S.-H. Chiu, Chem. Commun., 2007, 4122.

40 Y. Nagawa, J. Suga, K. Hiratani, E. Koyama and M. Kanesato, Chem. Commun., 2005, 749.

41 Unfortunately the photophysical properties of the $\mathrm{Li}^{\mathrm{I}}$ complex have not, to our knowledge, been reported.

42 W. Zhou, J. Li, X. He, C. Li, J. Lv, Y. Li, S. Wang, H. Liu and D. Zhu, Chem. - Eur. J., 2008, 14, 754.

43 S. Y. Hsueh, C. C. Lai and S. H. Chiu, Chem. - Eur. J., 2010, 16, 2997. 44 D. Curiel and P. D. Beer, Chem. Commun., 2005, 1909.

45 For selected examples of a related approach where metal ioncontaining molecular shuttles are monitored by a change in luminescence see: (a) H. Zhang, J. Hu and D. H. Qu, Org. Lett., 2012, 14, 2334; (b) H. Zhang, B. Zhou, H. Li, D.-H. Qu and H. Tian, J. Org. Chem., 2013, 78, 2091; (c) H. Li, X. Li, Z.-Q. Cao, D.-H. Qu, H. Ågren and H. Tian, ACS Appl. Mater. Interfaces, 2014, 6, 18921; (d) X. Ma, J. Zhang, J. Cao, X. Yao, T. Cao, Y. Gong, C. Zhao and H. Tian, Chem. Sci., 2016, 7, 4582.

46 B. R. Mullaney, A. L. Thompson and P. D. Beer, Angew. Chem., Int. Ed., 2014, 53, 11458.

47 C. Allain, P. D. Beer, S. Faulkner, M. W. Jones, A. M. Kenwright, N. L. Kilah, R. C. Knighton, T. J. Sørensen and M. Tropiano, Chem. Sci., 2013, 4, 489; M. J. Langton, O. A. Blackburn, T. Lang, S. Faulkner and P. D. Beer, Angew. Chem., Int. Ed., 2014, 53, 11463.

48 M. J. Langton, I. Marques, S. W. Robinson, V. Félix and P. D. Beer, Chem. - Eur. J., 2016, 22, 185; L. M. Hancock, E. Marchi, P. Ceroni and P. D. Beer, Chem. - Eur. J., 2012, 18, 11277.

49 (a) N. H. Evans and P. D. Beer, Org. Biomol. Chem., 2011, 9, 92; (b) J. Y. C. Lim, M. J. Cunningham, J. J. Davis and P. D. Beer, Dalton Trans., 2014, 43, 17274; (c) N. H. Evans, C. J. Serpell and P. D. Beer, Chem. Commun., 2011, 47, 8775; (d) N. H. Evans, C. J. Serpell, N. G. White and P. D. Beer, Chem. - Eur. J., 2011, 17, 12347; (e) N. H. Evans, H. Rahman, A. V. Leontiev, N. D. Greenham, G. A. Orlowski, Q. Zeng, R. M. J. Jacobs, C. J. Serpell, N. L. Kilah, J. J. Davis and P. D. Beer, Chem. Sci., 2012, 3, 1080.

50 J. Lehr, T. Lang, O. A. Blackburn, T. A. Barendt, S. Faulkner, J. J. Davis and P. D. Beer, Chem. - Eur. J., 2013, 19, 15898.

51 For recent reviews on the principles and applications of metallosupramolecular chemistry see: (a) M. M. J. Smulders, I. A. Riddell, C. Browne and J. R. Nitschke, Chem. Soc. Rev., 2013, 42, 1728; (b) N. J. Young and B. P. Hay, Chem. Commun., 2013, 49, 1354; (c) M. L. Saha, S. De, S. Pramanik and M. Schmittel, Chem. Soc. Rev., 2013, 42, 6860; (d) T. R. Cook and P. J. Stang, Chem. Rev., 2015, 115, 7001; (e) L. Chen, Q. Chen, M. Wu, F. Jiang and M. Hong, Acc. Chem. Res., 2015, 48, 201.

52 For selected reviews of interlocked metallo-supramolecular systems including pseudorotaxanes see: (a) S. J. Loeb, Chem. Commun., 2005, 1511; (b) S. J. Loeb, Chem. Soc. Rev., 2007, 36, 226; (c) H. Deng, M. A. Olson, J. F. Stoddart and O. M. Yaghi, Nat. Chem., 2010, 2, 439; (d) V. N. Vukotic and S. J. Loeb, Chem. Soc. Rev., 2012, 41, 5896; (e) J. Yang, J.-F. Ma and S. R. Batten, Chem. Commun., 2012, 48, 7899; (f) P. Wei, X. Yan and F. Huang, Chem. Soc. Rev., 2015, 44, 815.

53 G. J. E. Davidson and S. J. Loeb, Dalton Trans., 2003, 4319.

54 A. Noor, S. C. Moratti and J. D. Crowley, Chem. Sci., 2014, 5, 4283.

55 Y. Shi, Z. Yang, H. Liu, Z. Li, Y. Tian and F. Wang, ACS Macro Lett., $2015,4,6$.

56 A. Noor, W. K. C. Lo, S. C. Moratti and J. D. Crowley, Chem. Commun., 2014, 50, 7044.

57 S. Richter, J. Poppenberg, C. H. H. Traulsen, E. Darlatt, A. Sokolowski, D. Sattler, W. E. S. Unger and C. A. Schalley, J. Am. Chem. Soc., 2012, 134, 16289.

58 T. Heinrich, C. H.-H. Traulsen, M. Holzweber, S. Richter, V. Kunz, S. K. Kastner, S. O. Krabbenborg, J. Huskens, W. E. S. Unger and C. A. Schalley, J. Am. Chem. Soc., 2015, 137, 4382.

59 E. Viljoen, K. Zhu and S. J. Loeb, Chem. - Eur. J., 2016, 22, 7479.

60 V. N. Vukotic and S. J. Loeb, Chem. Soc. Rev., 2012, 41, 5896.

61 D. J. Mercer, V. N. Vukotic and S. J. Loeb, Chem. Commun., 2011, 47, 896. 
62 N. C. Frank, D. J. Mercer and S. J. Loeb, Chem. - Eur. J., 2013, 19, 14076. 63 L. Gao, Z. Zhang, B. Zheng and F. Huang, Polym. Chem., 2014, 5, 5734. 64 Z. B. Zhang, C. Y. Han, G. C. Yu and F. H. Huang, Chem. Sci., 2012, $3,3026$.

65 For recent reviews on the synthesis and applications of MOFs see: (a) H. C. Zhou, J. R. Long and O. M. Yaghi, Chem. Rev., 2012, 112, 673; (b) H. Furukawa, K. E. Cordova, M. O'Keeffe and O. M. Yaghi, Science, 2013, 341, 1230444; (c) O. K. Farha, Chem. Commun., 2015, 51, 3501; (d) A. H. Chughtai, N. Ahmad, H. A. Younus, A. Laypkov and F. Verpoort, Chem. Soc. Rev., 2015, 44, 6804; (e) A. Dhakshinamoorthy, A. M. Asiri and H. García, Angew. Chem., Int. Ed., 2016, 55, 5414; ( $f)$ Y. Cui, B. Li, H. He, W. Zhou, B. Chen and G. Qian, Acc. Chem. Res., 2016, 49, 483; (g) I. Nath, J. Chakraborty and F. Verpoort, Chem. Soc. Rev., 2016, 45, 4127; (h) Q. Wang, J. Bai, Z. Lu, Y. Pan and X. You, Chem. Commun., 2016, 52, 443.

66 (a) Y. Inokuma, S. Yoshioka, J. Ariyoshi, T. Arai, Y. Hitora, K. Takada, S. Matsunaga, K. Rissanen and M. Fujita, Nature, 2013, 495, 461; (b) M. Hoshino, A. Khutia, H. Xing, Y. Inokuma and M. Fujita, IUCrJ, 2016, 3, 139.

67 V. N. Vukotic, K. J. Harris, K. Zhu, R. W. Schurko and S. J. Loeb, Nat. Chem., 2012, 4, 456.

68 (a) V. N. Vukotic, C. A. O'Keefe, K. Zhu, K. J. Harris, C. To, R. W. Schurko and S. J. Loeb, J. Am. Chem. Soc., 2015, 137, 9643; (b) N. Farahani, K. Zhu, C. A. O'Keefe, R. W. Schurko and S. J. Loeb, ChemPlusChem, 2016, 81, 836.
69 K. Zhu, C. A. O'Keefe, V. N. Vukotic, R. W. Schurko and S. J. Loeb, Nat. Chem., 2015, 7, 514.

70 Q. Li, W. Zhang, O. Š. Miljanić, C. B. Knobler, J. F. Stoddart and O. M. Yaghi, Chem. Commun., 2010, 46, 380.

71 Q. Li, C.-H. Sue, S. Basu, A. K. Shveyd, W. Zhang, G. Barin, L. Fang, A. A. Sarjeant, J. F. Stoddart and O. M. Yaghi, Angew. Chem., Int. Ed., 2010, 49, 6751.

72 For selected examples of unusual stereoisomerism as a result of the mechanical bond see: (a) C. Yamamoto, Y. Okamoto, T. Schmidt, R. Jäger and F. Vögtle, J. Am. Chem. Soc., 1997, 119, 10547; (b) S. Meskers, H. Dekkers, G. Rapenne and J.-P. Sauvage, Chem. - Eur. J., 2000, 6, 2129; (c) S. A. Vignon, J. Wong, H. Tseng and J. F. Stoddart, Org. Lett., 2004, 6, 1095; (d) Y. Makita, N. Kihara, N. Nakakoji, T. Takata, S. Inagaki, C. Yamamoto and Y. Okamoto, Chem. Lett., 2007, 36, 162; (e) M. Alvarez-Pérez, S. M. Goldup, D. A. Leigh and A. M. Z. Slawin, J. Am. Chem. Soc., 2008, 130, 1836; $(f)$ A.-M. L. Fuller, D. A. Leigh and P. J. Lusby, J. Am. Chem. Soc., 2010, 132, 4954; $(g)$ R. J. Bordoli and S. M. Goldup, J. Am. Chem. Soc., 2014, 136, 4817; (h) T. Prakasam, M. Lusi, E. Nauha, J.-C. Olsen, M. Sy, C. Platas-Iglesias, L. J. Charbonnière and A. Trabolsi, Chem. Commun., 2015, 51, 5840; (i) E. A. Neal and S. M. Goldup, Angew. Chem., Int. Ed., 2016, 55, 12488.

73 For a recent example of a mechanically point chiral organocatalyst see: Y. Cakmak, S. Erbas-Cakmak and D. A. Leigh, J. Am. Chem. Soc., 2016, 138, 1749. 